Review

\title{
Nanobiosensing with Arrays and Ensembles of Nanoelectrodes
}

\author{
Najmeh Karimian, Ligia M. Moretto and Paolo Ugo * \\ Department of Molecular Sciences and Nanosystems, University Ca' Foscari of Venice, Via Torino 155-Mestre, \\ 30172 Venice, Italy; najmeh.karimian@unive.it (N.K.); moretto@unive.it (L.M.M.) \\ * Correspondence: ugo@unive.it; Tel.: +39-041-234-8503
}

Academic Editor: Huangxian Ju

Received: 28 November 2016; Accepted: 27 December 2016; Published: 30 December 2016

\begin{abstract}
Since the first reports dating back to the mid-1990s, ensembles and arrays of nanoelectrodes (NEEs and NEAs, respectively) have gained an important role as advanced electroanalytical tools thank to their unique characteristics which include, among others, dramatically improved signal/noise ratios, enhanced mass transport and suitability for extreme miniaturization. From the year 2000 onward, these properties have been exploited to develop electrochemical biosensors in which the surfaces of NEEs/NEAs have been functionalized with biorecognition layers using immobilization modes able to take the maximum advantage from the special morphology and composite nature of their surface. This paper presents an updated overview of this field. It consists of two parts. In the first, we discuss nanofabrication methods and the principles of functioning of NEEs/NEAs, focusing, in particular, on those features which are important for the development of highly sensitive and miniaturized biosensors. In the second part, we review literature references dealing the bioanalytical and biosensing applications of sensors based on biofunctionalized arrays/ensembles of nanoelectrodes, focusing our attention on the most recent advances, published in the last five years. The goal of this review is both to furnish fundamental knowledge to researchers starting their activity in this field and provide critical information on recent achievements which can stimulate new ideas for future developments to experienced scientists.
\end{abstract}

Keywords: nanoelectrode; ensemble; array; voltammetry; biosensor; bioelectroanalysis

\section{Introduction}

Owing to their characteristics of high sensitivity, compactness and easy integration with other analytical devices, arrays of nanoelectrodes offer great potential for bioanalytical applications [1-3]. In particular, the development of biosensing devices based on arrays of nanoelectrodes [4] in the form of nanodisks, nanowires, nanochannels and nanopores presents unique perspectives for the screening and detection at ultrahigh sensitivities of analytes of biological interest, which can include both biomacromolecules (e.g., proteins, polynucleotides) and small molecules (e.g., drugs, metabolites, toxic ions). Here we will use the definition nanoelectrode array (NEAs) and ensemble (NEE) to distinguish ordered from random arrangements of nanoelectrodes, respectively. From a general viewpoint, low cost, miniaturizability, easy use, no interference from colored or turbid matrices, applicability to raw samples for "in situ" and decentralized monitoring distinguish bioelectrochemical sensors with respect to classical instrumental methods such as spectroscopy, chromatography and mass-spectrometry. The nanostructuration of the sensor surface contributes in increasing the specific area available for the immobilization of high amounts of the biomolecules involved in the recognition event, while keeping the overall size of the sensor to very small figures [5-7]. Moreover, it is possible to engineer the sensor surface to separate, at the nanoscale range, the biorecognition and transduction events [8,9]. 
After a general introduction on the preparation, characterization and properties of NEEs/NEAs, this review focuses on current progresses on the analytical and biological application of NEEs/NEAs-based sensors. Attention is put in particular on arrays of metal or semiconductor nanoelectrodes. The quite broad topic concerning arrays of nanoelectrodes produced using carbon nanotubes alignment and similar procedures is beyond the scope of the present review. Readers interested in this topic are referred to specific articles and reviews, see e.g., [10-19].

\section{Template Ensemble of Nanoelectrodes}

The development of templated NEEs has made accessible to almost any chemical laboratory the preparation and use of nanoelectrodes. The first template synthesis of NEEs for electrochemical use was described by Menon and Martin [20], who deposited gold nanofibres with a diameter as small as $10 \mathrm{~nm}$ within the pores of track etched polycarbonate (PC) membranes by a chemical (electroless) method, obtaining a random ensemble of metal nanodisk electrodes surrounded by the insulating polymer. All the nanoelectrodes were interconnected to each other so that they all experienced the same electrochemical potential (see Figure 1).

(a)

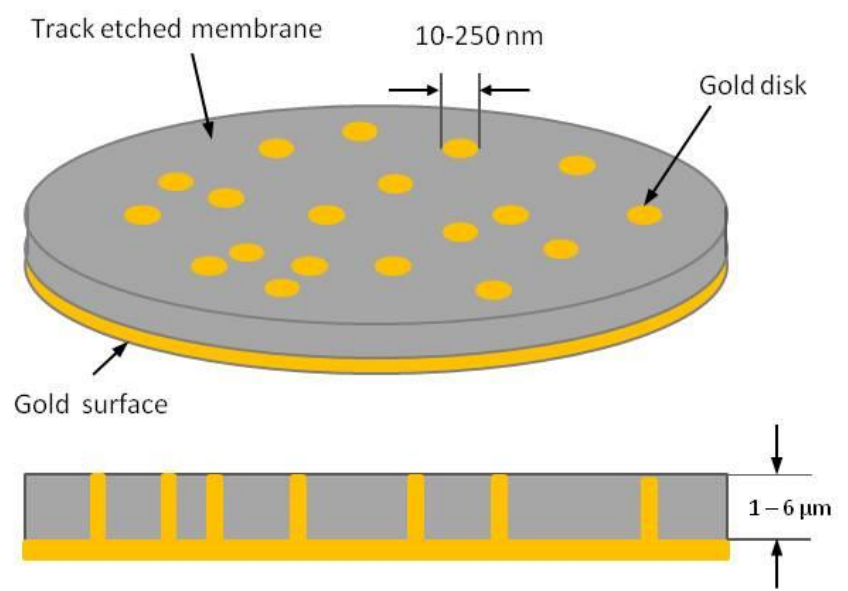

Figure 1. Schematic diagram of a nanoelectrode ensemble in a template membrane: (a) overall view; (b) cross section (redrawn and reprinted with permission from [4]).

In the membrane template synthesis the pores of a host material are used to direct the growth of new materials, typically gold and, later, other metals [20-22]. Various examples of membrane templated electrochemical deposition of nanowires of semiconductors [23], metals (e.g., $\mathrm{Ni}$ and $\mathrm{Co}$ ) [24], oxides and conducting polymers [1] have appeared in the literature. The metal fibers growth can be performed both by using electrochemical $[24,25]$ or electroless $[20,26,27]$ deposition methods.

In template deposition, the pore density in the template determines the number of metal nanoelectrode elements on the NEE surface and, correspondingly, the average distance between them, while the diameter of the pores in the template determines the diameter of the individual nanoelectrodes. Track-etched membranes with different pore diameters (e.g., 10, 30, $200 \mathrm{~nm}$ ) and average pore distance of $\geq 200 \mathrm{~nm}$ are commercially available.

\subsection{Template Electrochemical Deposition of Metals}

To perform the electrochemical deposition inside the pores of a nanoporous membrane it is necessary that one side of the membrane be used as the working electrode. This can be achieved by plasma or vacuum deposition of a thin layer of metal (typically 100-200 nm) on one side of the membrane, or placing the membrane in intimate contact with a solid electrode. Figure 2 shows three possible modes for template electrochemical deposition [28,29]: in Figure 2a, the membrane is pressed onto a solid electrode by a sponge drenched in the electrolyte [30], in Figure 2b,c adhesion between the 
membrane and underlying electrode is achieved thanks to a Nafion interlayer used as polyelectrolytic glue. The inner face of the membrane can be bare or pre-sputtered with a gold thin-layer, to improve electrical contact (Figure 2b,c, respectively). In electrochemical template deposition, the coated film is placed in an electrochemical cell, acting as the cathode and a counter electrode is the anode.

(a)
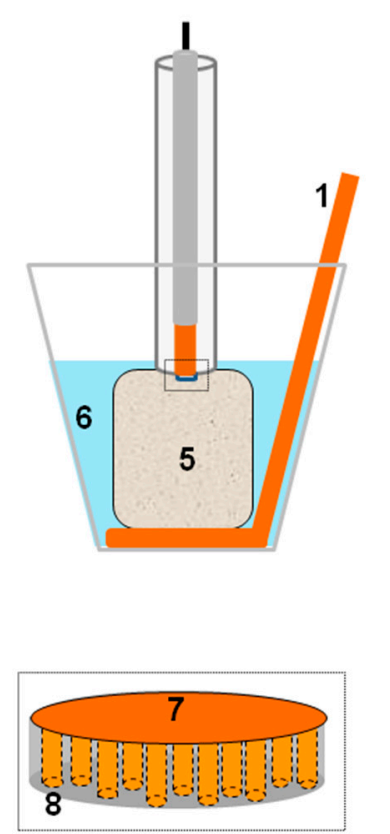

(b)
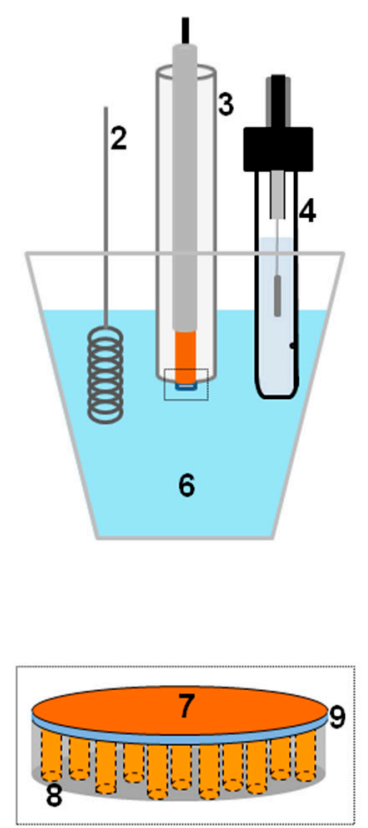

(c)
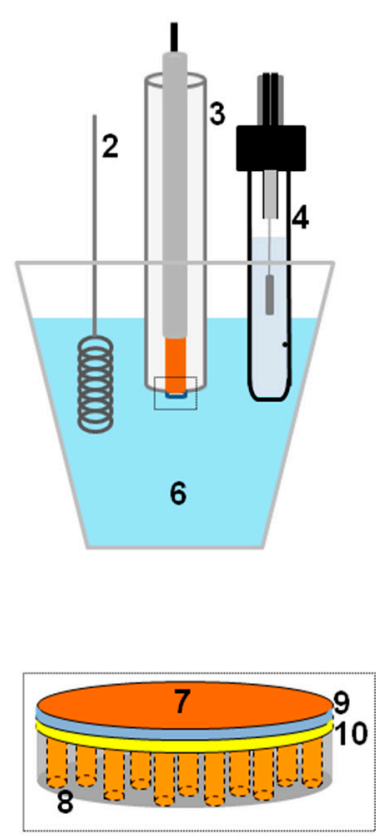

Figure 2. Scheme illustrating three template deposition methods used which differ for the way used to contact the PC membrane (8) to the flat disk Cu electrode (7). From left to right: (a) adhesion by the pressure furnished by the melamine foam (5); (b) adhesion by using a Nafion interlayer (9) as polyelectrolytic glue; (c) as (b), but using a PC membrane pre-sputtered with the gold interlayer (10). Other components: (1) $\mathrm{Cu}$ counter electrode; (2) Pt counter electrode; (3) working electrode; (4) $\mathrm{Ag} / \mathrm{AgCl} \mathrm{KCl}$ sat reference electrode; (6) $0.4 \mathrm{M} \mathrm{CuSO}_{4}, 0.01 \mathrm{M} \mathrm{H}_{2} \mathrm{SO}_{4}$ solution (reprinted with permission from [29]).

The deposition can be performed under potentiostatic or galvanostatic conditions. In the former case, it is possible to monitor the time course of the deposition and the progressive filling of the pores by analyzing the time transient current which is characterized by a sigmoidal shape $[24,28,31]$ (Figure 3). The initial current is characterized by an intense peak and a fast decay due to the depletion of metal ions following the fast initial deposition and the increase of resistance inside the pores of the membrane. In phase I the current reaches a plateau which corresponds to the progressive filling of the pores. In phase II, the current increases again because of the increase of the electrode area caused by the growing of the metal outside the pores. In this phase it is possible to observe caps on the tips of the nanowires with a typical mushroom shape [24]. Finally, the overgrown caps merge together producing an almost flat surface; this leads to a second plateau in the current transient (phase III). If the goal is the preparation of ensembles of nanodisk or nanowire electrodes, it is essential to stop the electrodeposition at the end of stage I, i.e., before the "mushroom caps" start to grow.

The electrodeposition of metals has been applied in order to obtain nanowires not only of gold, but also of other materials, such as, other metals (Co [24,32,33], Ni [24,28,34], Cu [24,28,29], Pt and Pd [35]), alloys (NiFe [33], FeSiB [34]) or salts $\left(\mathrm{Bi}_{2} \mathrm{Te}_{3}\right.$ [36], CdS [23]). Some recent papers deal with the theoretical modeling of electrochemical deposition in template membranes [37-42]. 


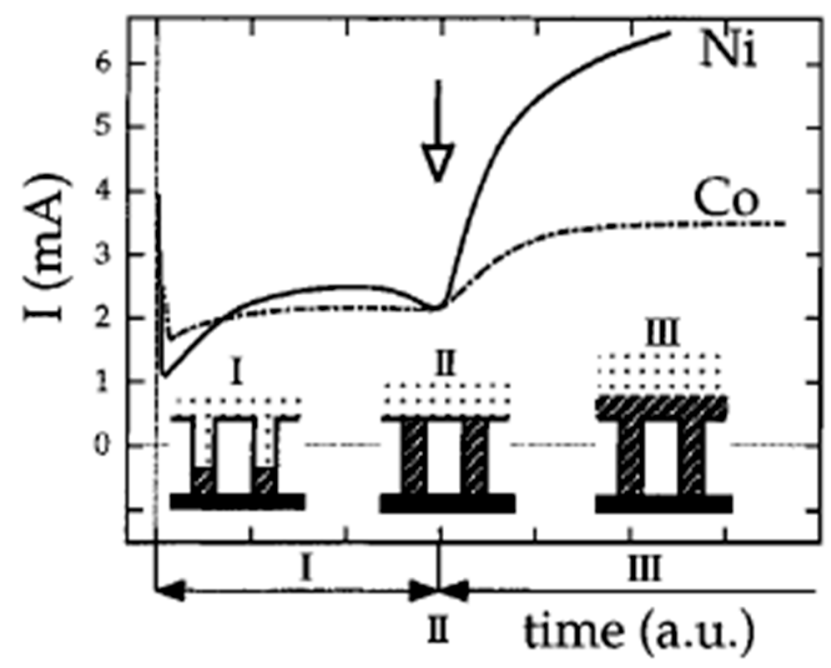

Figure 3. Electrochemical reduction current as a function of time for the potentiostatic platin of $\mathrm{Ni}$ and $\mathrm{Co}$ in the pores of PC membrane with $80 \mathrm{~nm}$ of nominal diameter (reprinted with permission from [24]).

\subsection{Template Electroless Deposition}

The electroless deposition involves the chemical reduction of a metal salt from the solution to an activated surface. Activation is performed by generating metal nuclei on the surface of a non-catalytic material. In the following chemical reaction, the metal ion is reduced more quickly at the sensitized surface so that this surface is rapidly plated with the desired metal [43].

The electroless deposition of gold in template membranes involves four steps $[1,20,44]$ : (i) "sensitization" of the membrane, adsorbing $\mathrm{Sn}^{2+}$ ions on the substrate; (ii) deposition of $\mathrm{Ag}$ nanoparticles by reduction of $\mathrm{Ag}^{+}$by the adsorbed $\mathrm{Sn}^{2+}$ ions; (iii) galvanic displacement of the $\mathrm{Ag}$ particles by reduction of a $\mathrm{Au}$ (I) solution; (iv) catalytic reduction of more gold on the deposited Au nuclei by addition of a reducing agent (formaldehyde). Note that this procedure applies to PC template membranes made hydrophilic by impregnation with the wetting agent polyvinylpyrrolidone, as usually done by track-etch membrane providers.

In contrast with the electrochemical template deposition, in the electroless method the metal layer grows from the catalytic nuclei, which are located on the pore walls, towards the center of the pores. When step (iv) is stopped at short times (e.g., 40-60 min at $\mathrm{pH} 10$ [26]) one can obtain hollow tubes instead of nanowires $[45,46]$ which can be further functionalized, for instance with the well-known thiol chemistry [47], for application as molecular sieves [48].

Other metals, such as $\mathrm{Cu}$ [49], Pd [50] and Ni-P [51] can also be deposited in polycarbonate templates by electroless deposition. In this case a suitable procedure for the desired metal might be applied.

Figure 4 shows the final structure of an ensemble of nanoelectrodes to be used as an electrode easy to handle [52]. The metalized membrane is sealed with an insulating film (d) in which a circular hole is punched, which defines the geometric area of the NEE $\left(\mathrm{A}_{\text {geom }}\right)$, that is the overall surface of the ensemble (nanoelectrodes and insulator between them) exposed to the solution. As a final step, the NEE assembly is heat-treated at $150{ }^{\circ} \mathrm{C}$ for $15 \mathrm{~min}$ to produce a water-tight seal between the gold nanowires and the surrounding polycarbonate.

Note that $\mathrm{A}_{\text {geom }}$ can be changed at pleasure $[53,54]$ without influencing the signal/noise (S/N) ratio which is typical of NEEs. The copper tape $(b)$ is used for electrical connection with the potentiostat. 


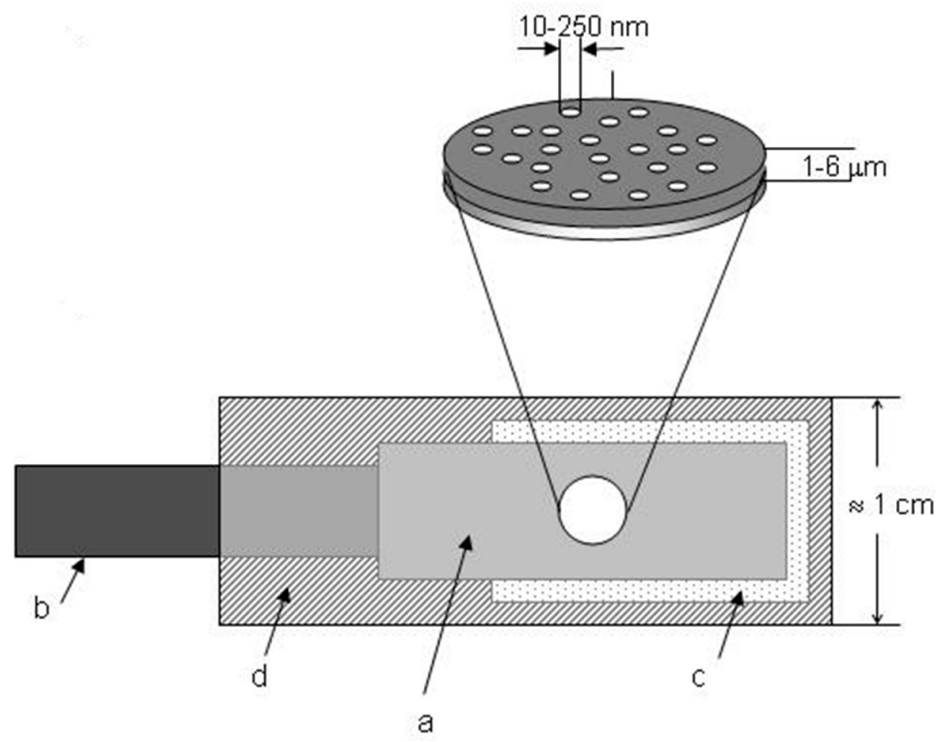

Figure 4. Schematic representation of a NEE, prepared by using a track-etched polycarbonate membrane as template: (a) track-etched golden membrane; (b) copper adhesive tape with conductive glue to connect to instrumentation; (c) aluminium adhesive foil with nonconductive glue; (d) thermoadhesive insulating tape (e.g., Monokote by Topflite). Note: the dimensions of the pores (nanofibres) are only indicative and not to scale (reprinted with permission from [52]).

\subsection{Combined Electroless-Electrochemical Deposition}

It was recently demonstrated that ensembles of $\mathrm{Au}$ nanowires prepared by template electroless deposition can be decorated electrochemically with metal and oxide nanostructures to obtain functional nanoarrays with special electrocatalytic or photocatalytic properties. By using electrochemically initiated oxide deposition [55] it was possible to prepare hierarchically branched $\mathrm{ZnO}$ nanostructures on $\mathrm{Au}$ nanowires, such as those shown in Figure 5.

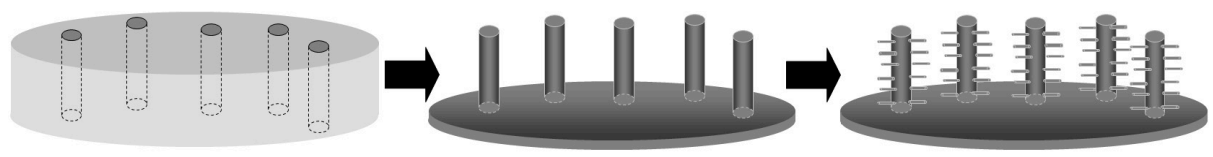

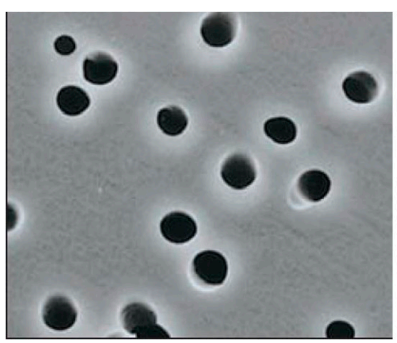

(a)

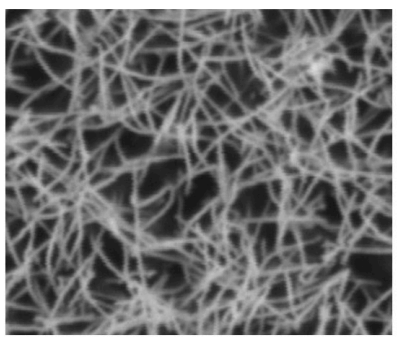

(b)

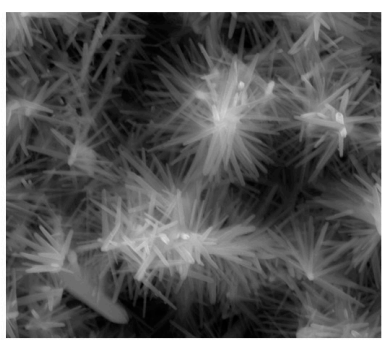

(c)

Figure 5. Scheme illustrating the preparation procedure used to obtain Au nanowires decorated with hierarchically branched $\mathrm{ZnO}$. (a) scheme and SEM image of the template membrane; (b) scheme and SEM image of an ensemble of gold nanowires obtained by electroless deposition; (c) scheme and SEM image of $\mathrm{ZnO}$ nanostructures grown electrochemically on the Au nanowires (reprinted with permission from [55]).

Very recently, it was demonstrated that closed bipolar electrochemistry can be successfully applied for the asymmetrical deposition of $\mathrm{Cu}_{2} \mathrm{O}$ and $\mathrm{TiO}_{2}$ on the two opposite tips of electroless templated 
Au nanowires [56]. Note that with this approach, the PC template membrane was kept in place and acted as separator between the two half-cells in the closed bipolar cell configuration. This geometry allowed to perform the bipolar deposition by applying a lower potential than the one required when operating with an open bipolar cell architecture.

\section{Diffusion at Arrays or Ensembles of Nanoelectrodes}

At the dimension range typical of nanoelectrodes (tens of $\mathrm{nm}$ ) edge effects are predominant and the diffusion from the bulk of the solution to individual nanoelectrodes is described by a radial geometry [57].

For instance, for a spherical microelectrode, the thickness, $\delta(t)$, of the diffusion layer around the electrode is given by Equation (1) [57]:

$$
1 / \delta(t)=\left[1 /(\pi \mathrm{Dt})^{1 / 2}\right]+1 / \mathrm{r}
$$

where $\mathrm{D}$ is the diffusion coefficient of the species, $\mathrm{t}$ is the time scale of the experiment, and $\mathrm{r}$ is the radius of the electrode. As the electrode decreases in size, the diffusion layer thickness approaches the size of the electrode dimension. The steady-state diffusion-controlled limiting current, I $(t \rightarrow \infty)$, is proportional to the inverse of the diffusion layer thickness, according to Equation (2) [57]:

$$
\mathrm{I}(\mathrm{t} \rightarrow \infty)=\mathrm{nFAC}^{\circ} / \delta(\mathrm{t} \rightarrow \infty)
$$

where $\mathrm{n}$ is the number of electrons exchanged, $\mathrm{F}$ is faraday constant, $\mathrm{A}$ is the electrode surface area, and $\mathrm{C}^{\circ}$ is the bulk concentration of the redox species. Dividing Equation (2) by A, it is evidenced that the smaller (nano)electrodes will provide higher current densities as a consequence of this enhanced mass transport component.

When the thickness of the diffusion layer is so small as to be comparable with the thickness of the electrical double layer (a few tens of $\mathrm{nm}$ ), electrostatic forces between the ions in the double layer and the redox analyte can accelerate (or retard) the flux of redox species with ionic charge opposite (or equal) to the ions in the double layer, so generating the conditions for a further enhancement (or lowering) of the mass transport to the nanoelectrode surface. Dickinson and Compton [58] presented a first attempt to analyze these effects, providing numerical solutions of the Poisson-Boltzman equation, calculated for hemispherical nanoelectrodes of vanishing size. Their study revealed significant effects of curvature on the diffuse double layer profiles, which become relevant for electrodes with radii less than $50 \mathrm{~nm}$, even in the presence of supporting electrolyte. An enhanced driving force is therefore expected for nanoelectrodes as compared to electrodes larger than 50-100 nm [58]. Studies on the kinetics of electron transfer at individual nanoelectrodes has been reviewed by Chen and Liu, with particular focus on the role of electrostatic interaction within the electrical double layer, and overlap between the diffusion layer and the electrical double layer [59]. Further studies have analyzed mass-transport processes at nanoelectrodes and their arrays [60].

Taking into account the overall diffusive process for a whole array of nanoelectrodes, it is evident that NEEs/NEAs can exhibit different voltammetric responses depending on the scan rate or the reciprocal distance among the nanoelectrodes [61-63]. The different limit situations are summarized in Figure 6a. When radial diffusion boundary layers totally overlap, i.e., when the diffusion hemisphere is larger than the mean hemidistance among the nanoelectrodes, NEEs behave as macroelectrodes with respect to the Faradic current (total overlap regime, peak shape voltammograms, case V). When the diffusion hemisphere becomes shorter (higher scan rates) or the hemidistance among nanodisks is larger, the voltammetric response is dominated by radial diffusion conditions at each element (pure radial regime, sigmoidally shaped voltammograms, case III). At very high scan rates, the linear active state is reached (case I), where linear diffusion is predominant at each nanodisk (peak shaped voltammograms, but with peak currents much smaller than case V). Obviously, intermediate situations can be also observed (case IV and II). 

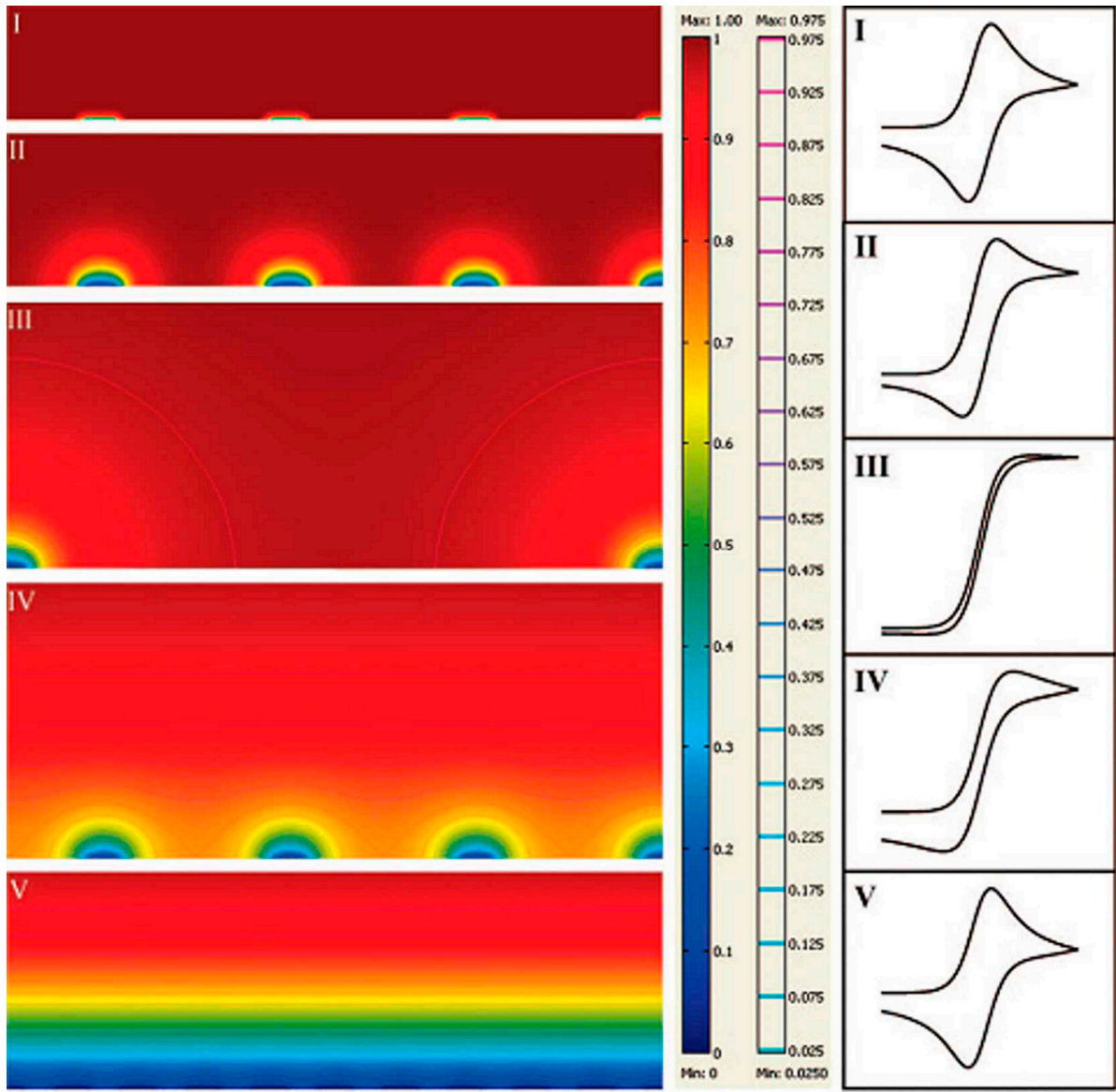

(a)

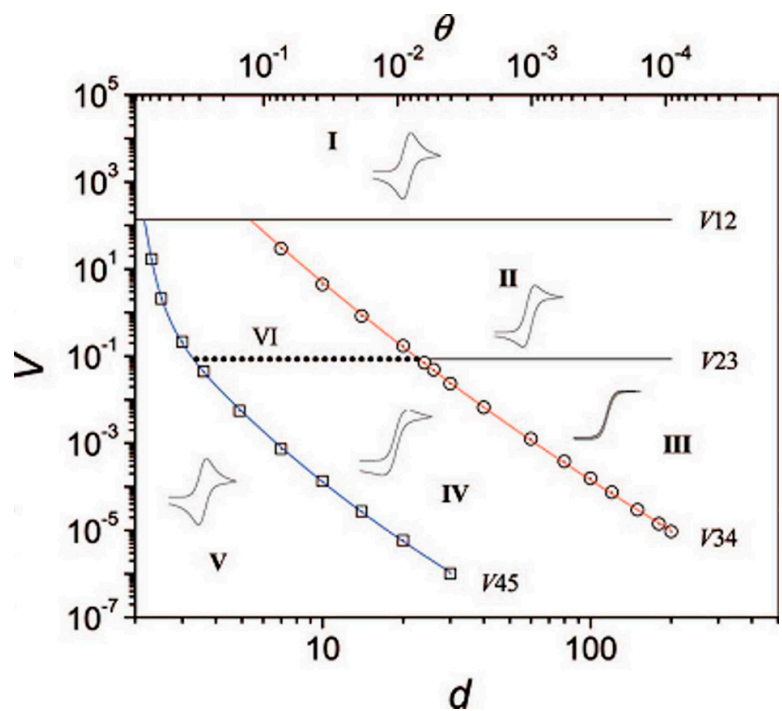

(b)

Figure 6. (a) Simulated concentration profiles and relevant voltammetric patterns, for microelectrode arrays representing the five main categories of possible diffusion modes (from I to V). In the scale bar, the red and blue colour represents the bulk concentration and zero concentration, respectively. The second scale bar represents a relative concentration scale for the contour lines. (b) Zone diagram of cyclic voltammetric behaviour at electrode arrays: $d$ is the centre-to-centre distance of individual electrodes in the array (measured in units of a), $\mathrm{V}$ is the dimensionless scan rate, and $\theta$ is the fraction of electrochemically active area in the array (reprinted with permission from [64]). 
Theoretical studies $[61,64-67]$ have examined in detail the role of the different diffusion regimes on the voltammetric responses recorded at arrays of ultramicro- and nanoelectrodes. In particular, Guo and Lindner [64] introduced a very useful zone-diagram where the combination of suitable dimensionless parameters allows one to determine the diffusion regime (and kind of voltammetric response) operative for a specific geometry of the array, at a specific voltammetric scan rate (see Figure 6b). The study was focused on arrays of microelectrodes, but can be extended to arrays of nanoelectrodes. Note that such a simulation was developed for arrays in which the effects at the border of the array are negligible, that is for arrays including a very large number of electrodes $[53,61,68]$. This condition can be achieved for small size arrays only if the electrodes size is very small, i.e., at nanoscale level. To make border effects negligible it is necessary to increase significantly the overall number of electrodes in the array; for instance in a $10^{4}$ electrodes squared array only $3.96 \%$ of them will be on the perimeter, while in a 100 electrodes array, $36 \%$ of the electrodes experience border effects.

A distance between the electrodes of 10r (where $r$ is the radius of the individual electrodes) is high enough to avoid cross-talking between the electrodes [61]. This means that if $r=10 \mu \mathrm{m}$, the side of a $10^{4}$ electrodes-array will be as large as $1 \mathrm{~cm}$. On the other hand, if $\mathrm{r}=0.1 \mu \mathrm{m}$, the side of the array, (with the same number of electrodes), will be lowered to $100 \mu \mathrm{m}$. This is particularly important dealing with electrochemical biosensors, where the immobilization of expensive biomolecules on the surface of the electrode is needed and miniaturization is a must.

On the other hand, in the case of arrays composed by a small number of nanoelectrodes, border effects play a relevant role. Under these conditions, when the overall size of the array is in the $\mu \mathrm{m}$ range, even for arrays operating in total overlap condition, sigmoidally shaped voltammograms are observed [7].

A recent paper presented quantitative theoretical investigation for development and validation of an analytical model for prediction of chronoamperometric responses at random arrays of micro- and nanodisk electrodes. This model was based on a 3D Brownian motion approach; it allowed to propose a simple analytical equation useful to predict the chronoamperometric behaviour of commonly used irregular arrays [69].

\section{Voltammetry with NEEs and NEAs}

\subsection{Voltammetry with NEEs}

The diffusion regime usually observed at NEEs fabricated from commercially available track-etched membrane is the total overlap regime [20], nevertheless, transition from this regime as a function of the nanoelements distance has been experimentally demonstrated using specially-made membranes [62] or by increasing the electrolyte viscosity [70].

For NEEs operating under total overlap diffusion conditions the Faradaic current $\left(\mathrm{I}_{\mathrm{F}}\right)$ is proportional to the total geometric area of the ensemble exposed to the sample solution ( $\mathrm{A}_{\text {geom }}$ area of the nanodisks plus the insulator area), while the double layer capacitive current $\left(\mathrm{I}_{\mathrm{C}}\right)$, which is the main component of the noise in electroanalytical chemistry, is proportional only to the active area $\left(\mathrm{A}_{\mathrm{act}}\right)$, that is the area of the metal nanoelectrodes exposed to the electrolyte [20].

The geometric area of a NEE is defined by the dimension of the hole punched into the insulator (see Figure 4). The active area is calculated from the membrane characteristics such as, pore density (q) and pore radius $(\mathrm{r})$, according to:

$$
\mathrm{A}_{\mathrm{act}}=\pi \cdot \mathrm{r}^{2} \cdot \mathrm{q} \cdot \mathrm{A}_{\text {geom }}
$$

The ratio between the active and the geometric area defines a key parameter named fractional electrode area $(\mathrm{f})$ :

$$
\mathrm{f}=\mathrm{A}_{\text {act }} / \mathrm{A}_{\text {geom }}
$$


Faradaic-to-capacitive current ratios at NEEs and conventional electrodes with the same geometric area are related by Equation (5) [71]:

$$
\left(\mathrm{I}_{\mathrm{F}} / \mathrm{I}_{\mathrm{C}}\right)_{\mathrm{NEE}}=\left(\mathrm{I}_{\mathrm{F}} / \mathrm{I}_{\mathrm{C}}\right)_{\mathrm{conv}} \cdot \mathrm{f}
$$

Equation (5) explains why detection limits (DLs) at NEEs can be 2-3 orders of magnitude lower than with conventional electrodes [20,71-73]. Since the improvement in $\mathrm{S} / \mathrm{N}$ ratios are strictly related to the fractional area, the electroanalytical performances of NEEs are not affected by any variation in the geometric area as long as the active area changes accordingly, i.e., the $\mathrm{f}$ parameter is kept constant $[53,54]$.

Some diagnostic criteria can be given to distinguish "good" NEEs from "bad" NEEs [44,52]. Voltammograms affected by a large capacitive current are indicative of poor sealing between the nanowires and the surrounding PC insulator and/or by heavy scratching of the PC membrane caused by an improper handling of the NEE. On the other hand, a radial diffusive contribution to the overall signal suggests a larger distance between the nanoelectrodes, possibly due to an only partial filling of the pores of the template.

\subsection{Ordered Arrays of Nanoelectrodes Fabricated by Nanolithography}

Top down techniques, such as ion beam lithography [3,74,75], electron beam lithography (EBL) [76], nanoimprint [77] or scanning probe lithography [78,79] allow one to achieve high resolution nanostructuring, providing a precise positioning and sizing down to a scale of a few nanometers. This spatial resolution capabilities have been indeed exploited to prepare ordered arrays of nanoelectrodes $[3,7,76]$.

Studies on arrays of gold nanolectrodes [68] demonstrated that PC can be used as an high resolution resist for e-beam lithography with the advantage of low cost and suitability for easy chemical functionalization with biomolecules $[9,80]$.

PC based nanoelectrodes are indeed fabricated by patterning arrays of holes in a thin film of PC spin-coated on a gold layer on $\mathrm{Si} / \mathrm{Si}_{3} \mathrm{~N}_{4}$ substrate. The PC surface is exposed to the e-beam and the tracks developed (etched) in $\mathrm{KOH}$ [68]. These holes can be used as openings for recessed nanoelectrodes, however, by further electrochemical deposition of gold, it is possible to fill partially or totally the holes up to obtain arrays of inlaid nanodisk electrodes (Figure 7). The perfect control of the geometry of the array and recession degree allows the full control of the diffusion regime at the so obtained NEA [68].
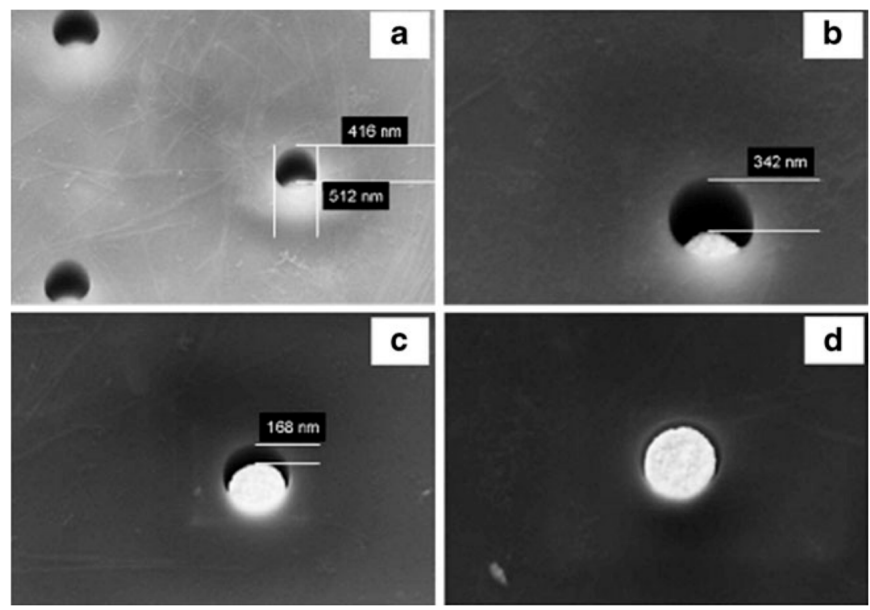

Figure 7. SEM images of NEAs with holes $500 \mathrm{~nm}$ in diameter with gold electrochemically deposited inside for $0 \mathrm{~s} \mathrm{(a);} 10 \mathrm{~s} \mathrm{(b);} 20 \mathrm{~s} \mathrm{(c);} \mathrm{and} 30 \mathrm{~s} \mathrm{(d).} \mathrm{Estimated} \mathrm{recession} \mathrm{depths:} \mathrm{(a)} 450 \mathrm{~nm}$; (b) $300 \mathrm{~nm}$; (c) $150 \mathrm{~nm}$; (d) $0 \mathrm{~nm}$ (reprinted with permission from [68]). 
Figure 8 demonstrates the scan rate independency of voltammetric signals at a NEA operating under pure-radial diffusive control; the geometric characteristics of the NEA and experimental conditions are indicated in the figure caption. Figure 8 refers to the case of an array of inlaid nanoelectrodes; it is worth to stress that, because of the nanolithographic process itself, quite often the nanoelectrodes so obtained can be slightly recessed, so that theoretical model for such geometries must be eventually taken into account $[68,75]$.

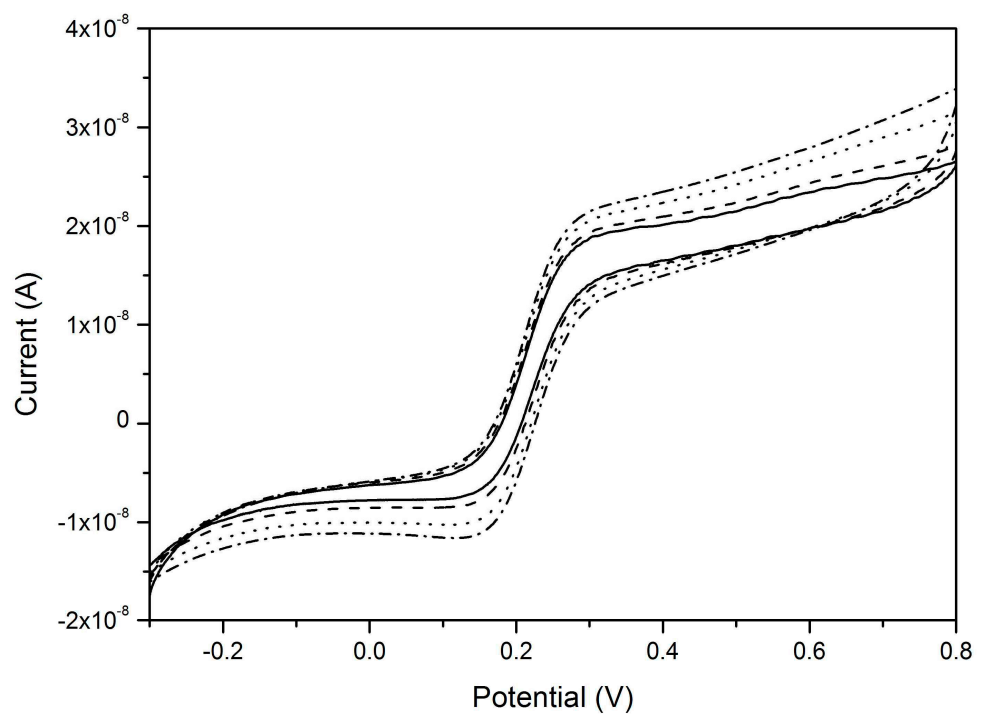

Figure 8. CVs recorded at a gold nanoelectrodes array in $10^{-4} \mathrm{M}$ ferrocene methanol and $0.5 \mathrm{M} \mathrm{NaNO}_{3}$. Scan rates: 5 (full line), 10 (dashed line), 20 (dotted line), and $50 \mathrm{mV} \cdot \mathrm{s}^{-1}$ (dash-dot line). Geometrical characteristics: nanodisk radius $=75 \mathrm{~nm}$, distance centre-to-centre $=3 \mu \mathrm{m}$, number of nanoelectrodes in the array $=1.1 \times 10^{4}$ (reprinted with permission from [68]).

The availability of NEEs (operating under totoal overlap diffusion conditions) and NEAs (operating under pure radial diffusion conditons), both fabricated with the same materials (namely, gold nanoelectrodes embedded in PC) has made it possible to perform the direct comparison between these two diffusion regimes in terms of current density yields. Note that with arrays and ensembles, the current density can be calculated in two ways, since the measured current can be normalized with respect to: (i) the active area of the array; (ii) the overall geometric area. The first mode, quantifies indeed the current density at each individual nanoelectrode while the latter defines the same parameter with respect to the array as a whole. Figure 9, taken from Moretto et al. [68], compares the current densities for a NEE and NEA made of Au-nanodiscs in PC, operating at $10 \mathrm{mV} \cdot \mathrm{s}^{-1}$ under total overlap and pure radial diffusion conditions, respectively. In Figure 9a, the current density is calculated with respect to the geometric area and in Figure $9 \mathrm{~b}$ with respect to the active area.

These plots show that the current density at the NEE is higher than the one at the NEA when the overall geometric area of the array is taken into account. On the other hand, this ratio is fully reversed in favour of the NEA (under pure radial diffusive control) if one evaluates the current density with respect to the active area. This is because at the NEE in total overlap condition, $100 \%$ of the geometric area contributes to produce the Faradic signal, while at the NEA under pure radial condition, the nanoelectrodes do not cross-talk and the transduction efficiency at each nanoelectrode reaches its maximum. Studies on arrays of gold nanolectrodes [68] demonstrated that PC can be used as an high resolution resist for e-beam lithography with the advantage of low cost and suitability for easy chemical functionalization with biomolecules $[9,80]$. 

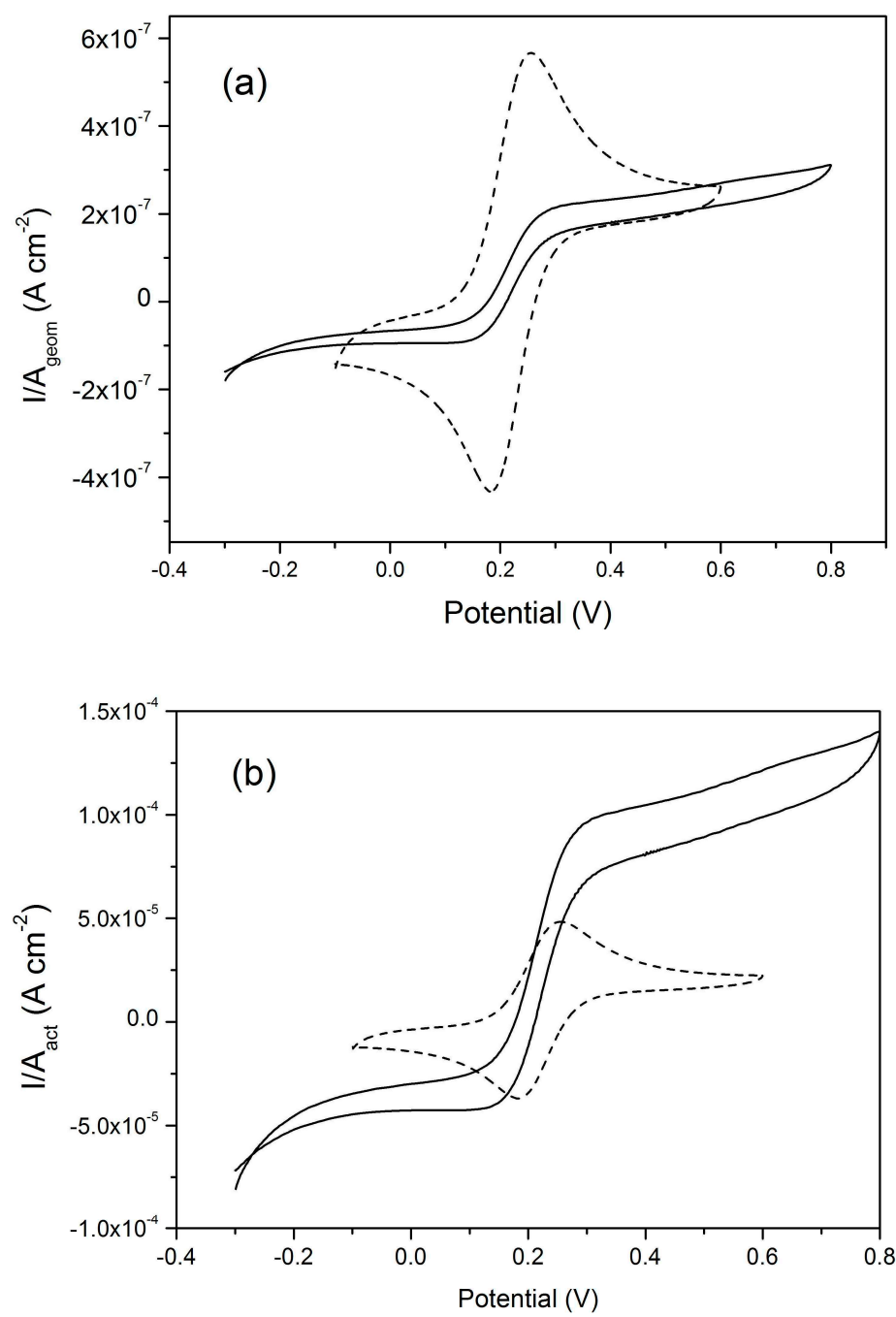

Figure 9. CVs recorded at a NEA (full line, see Figure 8) and at a NEE (dashed line, nanoelectrode radius $15 \mathrm{~nm}, A_{\text {geom }}=0.07 \mathrm{~cm}^{2}, \mathrm{~A}_{\text {act }}=4.5 \times 10^{-3} \mathrm{~cm}^{2}$ ) made of Au-nanodisks in polycarbonate, plotted using current densities calculated respect to the geometric area (a) and active area (b); scan rate $10 \mathrm{mV} \cdot \mathrm{s}^{-1}$, in $10^{-4} \mathrm{M}$ ferrocenemethanol. For further details, see the original article (reprinted with permission from [68]).

\subsection{Nanoelectrode Arrays of Boron-Doped Diamond}

A novel material which is increasingly used for the preparation of NEAs is boron-doped diamond (BDD). BDD is indeed a very attractive electrode material for the fabrication of nanostructures thanks to its excellent chemical and electrochemical stability, satisfactory electrical conductivity and wide potential window accessible [81]. The preparation of arrays and ensembles of BDD nanoelectrodes have been achieved by nanoparticles template procedure and nanosphere lithography $[82,83]$, by e-beam lithography [84] and by focused ion-beam milling [85]. BDD-NEAs have been characterized by scanning electrochemical microscopy (SECM) [86] and applied to study, at the nanoscale, relevant interfacial processes, such as adsorption phenomena at hydrogen- and oxygen- terminated BDD nano-surfaces [87] or to visualize ion-transfer across nano-interfaces between two immiscible electrolyte solutions [85].

It was recently shown that e-beam nano-lithographed BDD-NEAs can be used to finally tune electrochemically induced luminescence (ECL) as a function of the array geometry and/or composition of the electrolyte solution containing the luminophore $[\mathrm{Ru}(\mathrm{bpy})]_{3}{ }^{2+}$ and the co-reactant, tri-n-propylamine (TPrA) [88], as illustrated in Figure 10. In particular, NEAs with 16 different 
geometries were fabricated on the same BDD substrate, allowing one to detect simultaneously ECL emission from the different NEAs. The analysis of the ECL imaging data indicated that the ECL emitting zone scales inversely with the co-reactant concentration as well as significantly more intense ECL signals were detected for NEAs operating under overlap conditions.
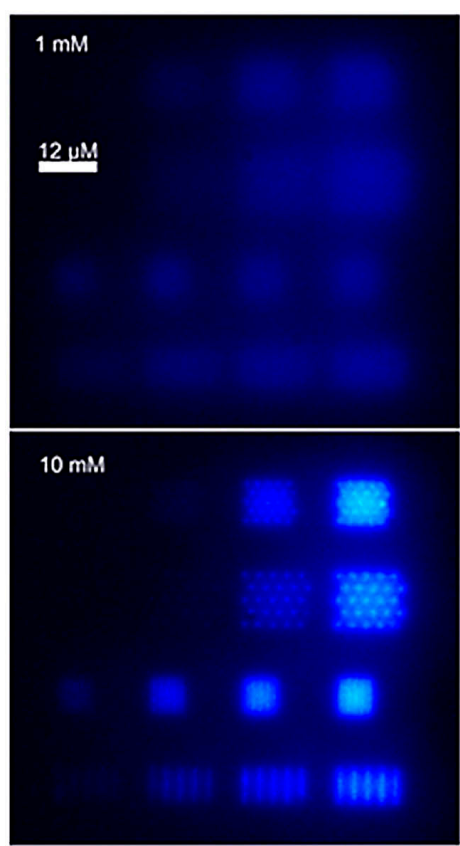
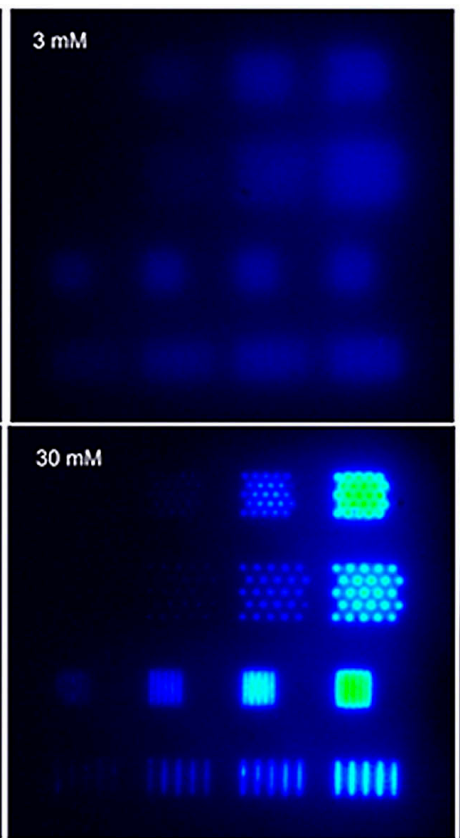

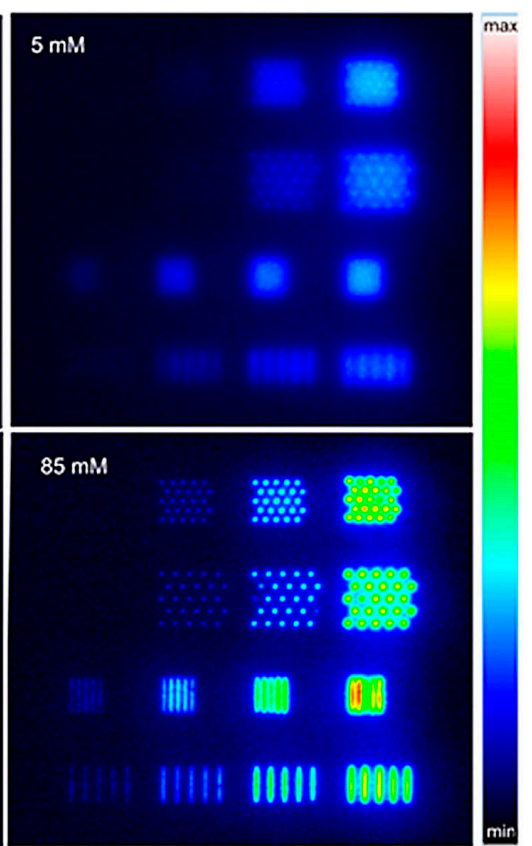

Figure 10. ECL images of a BDD-NEA obtained in phosphate buffer (pH 7.4) containing $1 \mathrm{mM}$ $\mathrm{Ru}(\mathrm{bpy})_{3}{ }^{2+}$ and increasing concentrations of TPrA (indicated in top-left corner of each box). Images were recorded in the dark with a $\times 50$ objective when applying a constant potential of $1.2 \mathrm{~V}$ vs. $\mathrm{Ag} / \mathrm{AgCl} / \mathrm{KCl}$. All images were coded according to the same false colour scale (right) (reprinted with permission from [88]).

These plots show that the current density at the NEE is higher than the one at the NEA when the overall geometric area of the array is taken into account. On the other hand, this ratio is fully reversed in favour of the NEA (under pure radial diffusive control) if one evaluates the current density with respect to the active area. This is because at the NEE in total overlap condition, 100\% of the geometric area contributes to produce the Faradic signal, while at the NEA under pure radial condition, the nanoelectrodes do not cross-talk and the transduction efficiency at each nanoelectrode reaches its maximum.

\subsection{Electron Transfer Kinetics}

NEEs/NEAs are very sensitive to the electron transfer kinetics [20]. According to model proposed by Amatore et al. [89], as well as to more recent theoretical models [64-66], a NEE behaves as a partially blocked electrode (PBE), whose current response is identical to that of a naked electrode of the same overall geometric area, but with a smaller apparent rate constant $\left(\mathrm{k}^{\circ}\right.$ app $)$ for the electron transfer, which decreases as the coverage of the surface increases. According to this model, the nanodisks electrodes are the unblocked surface and the template membrane is the blocking material. The apparent rate constant $\left(\mathrm{k}^{\circ}\right.$ app $)$ is related to the true standard rate constant by the following equation:

$$
\mathrm{k}^{\circ}{ }_{\text {app }}=\mathrm{k}^{\circ}(1-\vartheta)=\mathrm{k}^{\circ} \mathrm{f}
$$

where $\vartheta=\left(\mathrm{A}_{\text {geom }}-\mathrm{A}_{\mathrm{act}}\right) / \mathrm{A}_{\text {geom }}$ and $\mathrm{f}$ is the fractional electrode area (see Equation (4)). 
From an analytical viewpoint, the operativity of Equation (6) means that high faradaic peak currents are observed at NEEs only for redox couples with "very reversible" behavior. In cyclic voltammetry $(\mathrm{CV})$ in fact, the reversibility of a redox system depends on the $\mathrm{k}^{\circ}$ value and on the scan rate (v). Using conventional electrodes, reversible patterns are obtained when:

$$
\mathrm{v}^{1 / 2} \leq\left(\mathrm{k}^{\circ} / 0.3\right)
$$

but if NEEs are used, $\mathrm{k}^{\circ}$ is substituted by $\mathrm{k}^{\circ}{ }_{\mathrm{app}}$, and the previous relation becomes:

$$
\mathrm{v}^{1 / 2} \leq\left[\left(\mathrm{k}^{\circ} \mathrm{f}\right) / 0.3\right]
$$

Considering that mean $\mathrm{f}$ values ranges from $10^{-2}$ to $10^{-3}$, from Equation (8) we can conclude that the scan rate value that defines the transition between reversible and quasi-reversible behavior is placed at a scan rate 2-3 orders of magnitude lower than the value requested for conventional electrodes. This is a limitation to be seriously taken into account when trying to optimize NEEs for bioanalytical application, since it is important to consider the contrasting effect both of the increased $\mathrm{I}_{\mathrm{F}} / \mathrm{I}_{\mathrm{C}}$ value and the apparent slowing down of the electron transfer kinetics. On the other hand, from a mechanistic viewpoint, it is an advantage since it means that with NEEs it is easier to measure experimentally very large $\mathrm{k}^{\circ}$ values [57]. By the analysis of $\Delta \mathrm{E}_{\mathrm{p}}$ dependence on the scan rate [90] and using suitable working curves [91], smaller $\mathrm{k}^{\circ}$ app values are obtained and converted to larger $\mathrm{k}^{\circ}$ by Equation (6) [89].

\section{From 2D- to 3D-NEAs}

Depending on the final surface morphology of the NEE, one can prepare two-dimensional nanoelectrode ensembles (2D-NEEs), made of ensembles of nanodisk electrodes, or three-dimensional nanoelectrode ensembles (3D-NEEs), made of nanofibers [92-95]. The small surface area of the NEEs can be increased in a controlled way by suitable etching, in order to partially remove the upper layers of the polycarbonate template membrane. In other words, NEEs of metal nanodisks, prepared by electroless or electrochemical template deposition within the pores of track-etched polycarbonate membranes, are treated with oxygen plasma [92] or with solvent mixtures such as $\mathrm{CH}_{2} \mathrm{Cl}_{2} / \mathrm{C}_{2} \mathrm{H}_{5} \mathrm{OH}$ mixtures [5,96], to achieve the controlled etching of the template. This causes the structure of the final ensemble to change from a 2D flat structure into a 3D one [5]. As illustrated in Figure 11, depending on whether the template is kept on site, partially etched or fully removed, it is possible to obtain nanoelectrodes ensembles with very different geometries. 3D-NEEs are powerful electrode systems with a high active surface suitable for functionalization and extreme miniaturization. For 3D-NEEs the measurement of the active area is necessary to correlate the intensity of electrochemical signals with $A_{\text {act }}$ values. This parameter can be obtained by AC electrochemical impedance spectroscopy [97] or by measuring: the double layer charging current [29] or the total charge associated to gold oxide stripping [98] or to other redox processes relevant to adsorbed species, such as polyoxometallates [5].

(a)

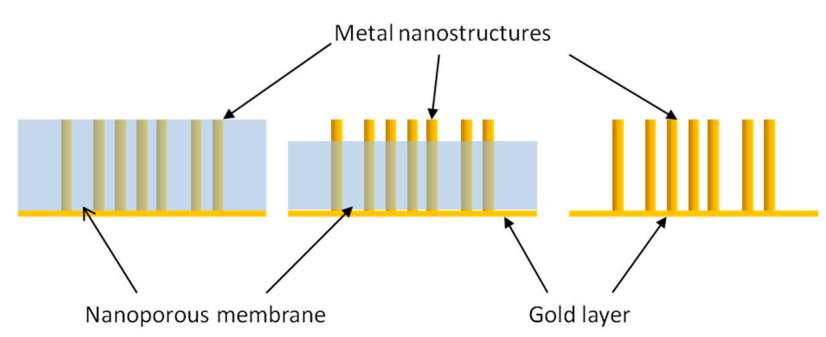

Figure 11. Different geometries for template nanoelectrode ensembles: (a) ensemble of nanodisks; (b) ensemble of partially naked nanowires; (c) ensemble of completely naked. 
In order to take maximum advantage of the use of 3D-NEEs, one has to take into account that their electrochemical response is influenced by the high density of metal nanofibers $\left(\sim 6 \times 10^{8}\right.$ nanofibers $\left.\mathrm{cm}^{-2}\right)$, and possible overlap of the diffusion layers [99]. The parameters which rule the electrochemical behavior of 3D-NEEs were studied by De Leo and coworkers [5]. In this work it was shown that for fast redox couples such as ferrocene derivatives, faradaic peak currents are not influenced by the etching process, while double-layer capacitive currents increase. Since 3D-NEEs behave as PBE, the true kinetic constant is indeed substituted by an 'apparent kinetic constant' (see Equation (6)). However, for a very fast redox couple, the influence of the change of $k^{\circ}$ app values by changing $\mathrm{f}$ cannot be appreciated experimentally at the scan rates typically used for cyclic voltammetry $\left(100 \mathrm{mV} \cdot \mathrm{s}^{-1}\right.$ or lower). As predicted on the basis of the theoretical model by Amatore et al. [89], the situation changes dramatically for redox species characterized by slow heterogeneous electron transfer kinetics.

The kinetic limitation causes a considerable torsion of the lines of flux near each nanoelectrode element, thus imposing a local rate of diffusion considerably larger than the one far from each electrode. As a consequence each nanoelectrode behaves individually with respect to the heterogeneous kinetics. Figure 12 shows a sketch summarizing the effect of differences in heterogeneous rate constants on the electrochemical behavior of 3D-NEEs. Recently, a general theoretical treatment of the electrochemical behavior of arrays with 2D and 3D geometries have been proposed by Amatore and coworkers [100].

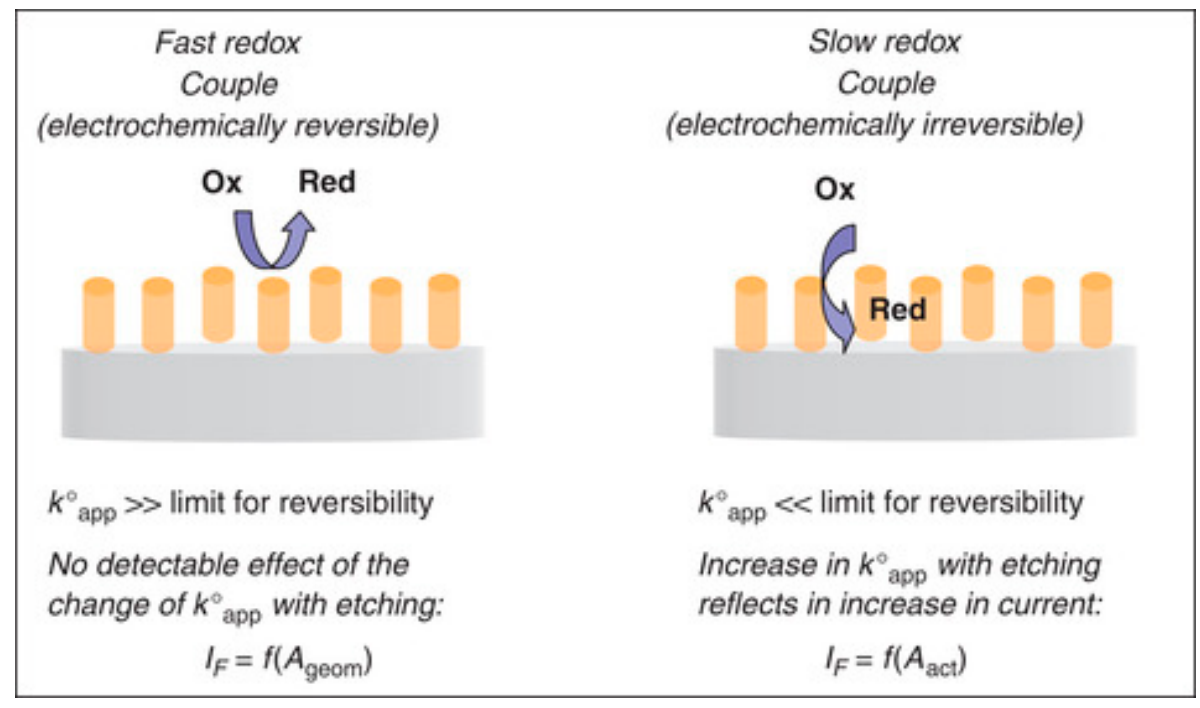

Figure 12. Sketch of the effect of different electron transfer kinetics on electrochemical responses at three-dimensional nanoelectrode ensemble (3D-NEE) (reprinted with permission from [101]).

\section{Bio-Analytical Applications of NEEs/NEAs: First Studies}

The improved signal-to-noise $(\mathrm{S} / \mathrm{N})$ ratio and extreme miniaturization typical of 2D-NEEs, have made them particularly attractive for analytical applications to detect electroactive species at low concentration levels. First studies performed at the end of the 1990s-beginning 2000s have proven that NEEs are powerful electroanalytical tools for the analysis of small redox molecules with reversible electrochemical behavior, such as ferrocene derivatives, ruthenium complexes, phenothiazines or viologens $[20,72,73]$. It was demonstrated that NEEs can be used for determining iodide anions in ophthalmic drugs [44] or in natural waters [102]. Moreover, they can be successfully applied also for the direct detection of trace levels of the complex redox bio-macromolecules such as the heme-protein cytochrome $c[53,103]$. The application of NEEs has been studied more recently to perform the analysis of heavy metals and toxic elements at trace and ultra-trace concentration levels. Mardegan et al. demonstrated the applicability of NEEs to perform trace analysis of arsenic and its redox speciation by anodic stripping-square wave voltammetry (AS-SWV) [104]. For analyzing heavy metal ions, NEEs 
can be modified by deposition of a Bi film, so extending the cathodic limit of the accessible potential window, thanks to the high overpotential of Bi for the hydrogen evolution reaction. By this way it was possible to apply NEEs for the anodic striping voltammetric determination of trace levels of lead(II) [105].

In other cases, it is convenient to exploit for analytical purposes the larger surface area of 3D-NEEs. For example, Stortini et al. demonstrated efficient sensing performances of copper 3D-NEEs with respect to nitrate determination at concentration levels as low as few $\mu \mathrm{M}$ [29]. Similarly, Cao et al. demonstrated that 3D-NEEs composed of gold nanowires can be successfully applied to the analysis of the antibiotic daunorubicin [98].

The small active area of 2D-NEEs can be a limit also when the gold nanodisks are used as substrate for the immobilization of bioactive molecules, as typically done for preparing electrochemical biosensors; also in these cases the use of 3D-NEEs is advisable. The gold surface of 3D-NEEs have been used for the determination of ovarian cancer marker mucin-16 (MUC16) by Viswanathan et al. [106]. These authors developed an electrochemical immunosensor using monoclonal anti-mucin-16 antibodies ( $\alpha$ MUC-16) bonded on liposomes in which ferrocene carboxylic acid is encapsulated; $\alpha$ MUC-16 was also immobilized on a cysteamine self-assembled monolayer (SAM) on the gold surface of 3D-NEE via cross-linking with carbodiimide (EDC) and N-hydroxysulfosuccinimide (Sulfo-NHS). A sandwich immunoassay was performed on $\alpha$ MUC-16 functionalized 3D-NEE with MUC-16 and immunoliposomes using differential pulse voltammetry (DPV) as the detection technique. This example shows the possibility to exploit the increased Au surface of 3D-NEEs to increase the amount of adsorbed biomolecules, however such an improved surface area comes at the expense of an increased capacitive current. This is not a major problem for the direct detection of molecules adsorbed on the nanowires, since both the amount of redox species and the capacitive current scale proportionally with the active area. On the other hand, when the detection involves a diffusion step (of the analyte, mediator or substrate) the etching can cause a significant decrease of the $S / \mathrm{N}$ ratio, as described in Section 5. In order to overcome such a drawback, Ugo and coworkers proposed an original approach in which the biorecognition element is immobilized on the polymeric template of the NEE. In such a design, the transducer and the biorecognition elements are not overlapped but integrated in strict proximity. This approach, besides maintaining the excellent detection limits of 2D-NEEs, greatly increases the amount of biomolecules bound on the NEE, since the polycarbonate surface is 2-3 orders of magnitude larger than the gold surface of the nanoelectrodes.

This can be done by exploiting the functional groups inherently present in the template matrix. Indeed, titrations with thionin acetate indicated that a surface concentration of - $\mathrm{COOH}$ in the order of $9.7 \times 10^{-10} \mathrm{~mol} \cdot \mathrm{cm}^{-2}$ is naturally present on the surface of track-etched polycarbonate; this number can be increased to $3.4 \times 10^{-9} \mathrm{~mol} \cdot \mathrm{cm}^{-2}$ by controlled oxidation with $\mathrm{KMnO}_{4}[107,108]$. Mucelli et al. proposed this strategy for the preparation of an immunosensor for the determination of the HER2 receptor, overexpressed in certain kinds of breast cancer [9]. At first, the specific antibody trastuzumab is immobilized on the PC of a NEE. Later on, it is incubated with the sample to capture the target protein HER2. The captured protein is then reacted with a different primary antibody (namely, monoclonal CB-11) which finally binds a secondary antibody labeled with horseradish peroxidase (HRP). The electrochemical signal is generated by methylene blue (MB) added to the solution as redox mediator, which shuttles electrons from the nanoelectrode elements to the HRP, when the latter reacts with its substrate, i.e., $\mathrm{H}_{2} \mathrm{O}_{2}$. A similar approach has been used for determining the presence of egg yolk as binder in ancient tempera paintings [109]. The detected analyte was the glycoprotein immunoglobulin IgY which is the main immunoglobulin in chicken eggs. In this approach, which is schematized in Figure 13, IgY is captured by the polycarbonate surface (A), the electrode is then incubated with anti-IgY labeled with HRP (Anti-IgY-HRP) (B) and, finally, the presence of the label $\mathrm{HRP}$, is detected by adding the enzyme substrate $\mathrm{H}_{2} \mathrm{O}_{2}$ and a mediator (C). The main advantage of this approach lies on the fact that the antigen is bound directly on the polycarbonate surface, reducing the analytical steps and the reagents required. 
(a)

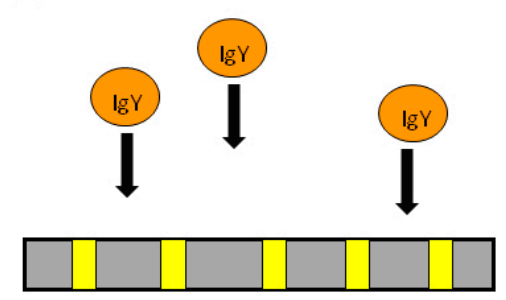

(b)

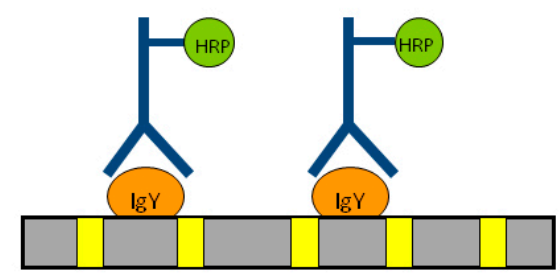

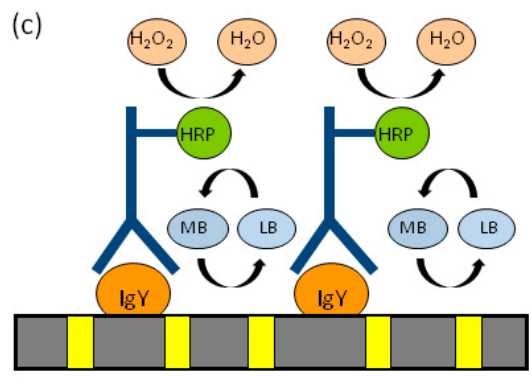

Figure 13. Schematic representation of the analytical protocol used to detect immunoglobulin IgY, extracted from tempera paints. MB and LB are the oxidized and reduced forms of the redox mediator methylene blue and HRP is horseradish peroxidase, used as enzymatic label for the anti-IgY antibody (a) capture of immunoglobulin IgY on the polycarbonate of the NEE; (b) molecular recognition by anti-IgY labeled with HRP; (c) generation of the electrocatalytic cycle by adding the enzyme substrate $\mathrm{H}_{2} \mathrm{O}_{2}$ and the mediator MB. (reprinted with permission from [109]).

Also other molecules in the sample can spontaneously bind to the polycarbonate, however only IgY is recognized by the HRP-labeled anti IgY, which finally generates the electrocatalytic signal. This allowed to develop a diagnostic scheme able to distinguish qualitatively, but with high precision, egg-yolk tempera (which contains IgY) from other kind of tempera (not containing IgY) as well as oil or acrylic paints. It is worth pointing out that the application of this geometry for the sensitive detection of DNA hybridization was also demonstrated using 2D-NEEs or NEEs decorated with Au-nanoparticles [107].

\section{Most Recent Advances in Biosensing with NEEs/NEAs}

In this section we highlight very recent advances dealing with the use of nanoelectrode arrays and ensembles as sensing platforms suitable for therapeutic, diagnostic and bioanalytical application. In Tables 1-3 are listed and briefly commented examples of researches in this field published in the last five years. The nanoelectrode arrangements studied include both NEEs and NEAs structures composed by nanodisks, nanowires, nanochannels, nanopores and nanotubes. These examples demonstrate the variety of geometries and morphologies of nanoelectrode structures that can be successfully applied for biosensing purposes, offering excellent detection capabilities for analyzing and monitoring different biomarkers and proteins, DNA, neurotransmitters, metabolites, pharmaceutical or toxic compounds.

Concerning the direct detection of small molecules (see Table 1) many recent researches focused on the use of 3D-arrays of nanowires, which provided improved detection capabilities for metronidazole [110], arsenic [111], $\mathrm{NO}_{3}{ }^{-}$[29] and glucose [112]. NEAs of gold [113] or BDD [114] were successfully used for the analyses of dopamine and related compounds. Properties of $\mathrm{TiO}_{2}$ nanotube arrays have been exploited to detect trace level of the hair dye basic-brown 17 [115].

Both NEEs and NEAs have been functionalized to develop nanoelectrode-based biosensors suitable for advanced molecular diagnostics (see Table 2). In some cases, the functionalization of nanowire electrodes was performed. For instance, Au-coated silicon nanowires were functionalized with artificial peptides to detect RNA as response element for HIV-1 diagnostics [116]. Anti prostate-specific 
antigen (PSA) was electrodeposited with polypyrrole on 3D-gold nanowires to develop a label free immunosensor for PSA antigen [117]. 3D-gold NEEs modified with molecular imprinted poly(o-phenylenediamine) (PoPD) were exploited for aflatoxin B1 detection, reaching a detection limit of $19 \mathrm{fg} \cdot \mathrm{mL}^{-1}$ by electrochemical impedance spectroscopy [118]. Molecular imprinted polyphenol was deposited on ensembles of Au-nanowires to develop a sensor for epithelial ovarian cancer antigen-125 [119].

The strategy based on the immobilization of the biorecognition layer on the polycarbonate of 2D-NEEs was applied to detect DNA hybridization [120]. In particular, the effect of the possible activation of the PC surface by oxidation with $\mathrm{KMnO}_{4}$ on the immobilization of SS-DNA was examined. It was shown that this treatment increases the number of reactive $\mathrm{COOH}$ groups present on the PC. However, it reflects in an increase in the capacitive current, due to partial desealing of the PC surrounding the gold nanodisks. Therefore care must be put in balancing the two effects to optimize the sensor's performances [120]. A novel immunosensor for celiac disease diagnostic was based on electrogenerated chemiluminescence (ECL) at NEEs [121]. The target analyte, namely tissue transglutaminase antibody (anti-tTG) was captured by tissue transglutaminase (tTG) immobilized on the PC of the track-etched template membrane. Interaction of the target analyte with a suitable secondary antibody functionalized with a ruthenium label allowed quantification of anti-tTG. This was possible by ECL generation via the electrochemical oxidation of tripropylammine at the nanoelectrodes, this molecule acting both as co-reactant and redox mediator. A wide dynamic range and a low detection limit $\left(0.5 \mathrm{ng} \cdot \mathrm{mL}^{-1}\right)$ characterized the sensor, which has been successfully applied in real samples such as blood serum of celiac patients. The PC surface of NEEs has been exploited also for immobilization of glucose oxidase in a miniaturized NEE-based enzymatic glucose sensor [54].

Table 1. Articles published in the years 2012-2016, dealing with the application of NEEs/NEAs for the direct detection of small molecules of biological interest.

\begin{tabular}{|c|c|c|c|c|}
\hline Nanosensor Type & Nanosense Platform & Target & Notes & Ref. \\
\hline NEEs & 3D-gold nanotubes & Metronidazole & DL $0.1 \mathrm{nM}$ & {$[110]$} \\
\hline NEAs & $\begin{array}{l}\text { 3D- ordered freestanding } \\
\text { porous platinum }(\mathrm{Pt}) \\
\text { nanowire array electrode }\end{array}$ & Glucose, $\mathrm{H}_{2} \mathrm{O}_{2}$ & $\begin{array}{l}\text { Effect of granular and rougher } \\
\text { porous nanowire surface on } \\
\text { the bioactivity of glucose } \\
\text { oxidase is examined }\end{array}$ & [112] \\
\hline NEAs & $\begin{array}{c}\text { Nanocrystalline } \\
\text { boron-doped diamond } \\
\text { nanoelectrode } \\
\text { arrays(BDD-NEAs) }\end{array}$ & Dopamine & $\begin{array}{l}\text { Appropriate termination } \\
\text { by choosing oxygen (O-) } \\
\text { terminated BDD-NEAs, } \\
\text { DL } 100 \mathrm{nM}\end{array}$ & [114] \\
\hline NEAs & $\begin{array}{c}\text { Self-organized } \mathrm{Ti} / \mathrm{TiO}_{2} \\
\text { nanotubular array }\end{array}$ & Hair dye basic brown 17 & DL $1.3 \times 10^{-7} \mathrm{M}$ & [115] \\
\hline NEAs & Pt nanoband electrode & $\begin{array}{c}\text { Detection of, ferrocene } \\
\text { carboxylic acid, hydrogen } \\
\text { peroxide and 4-aminophenol }\end{array}$ & $\begin{array}{l}\text { Chronoamperometric and } \\
\text { cyclic voltammetric detection }\end{array}$ & [122] \\
\hline
\end{tabular}


Table 2. Articles published in the years 2012-2016, dealing with the application of NEEs/NEAs for the development of electrochemical sensors for biomacromolecules.

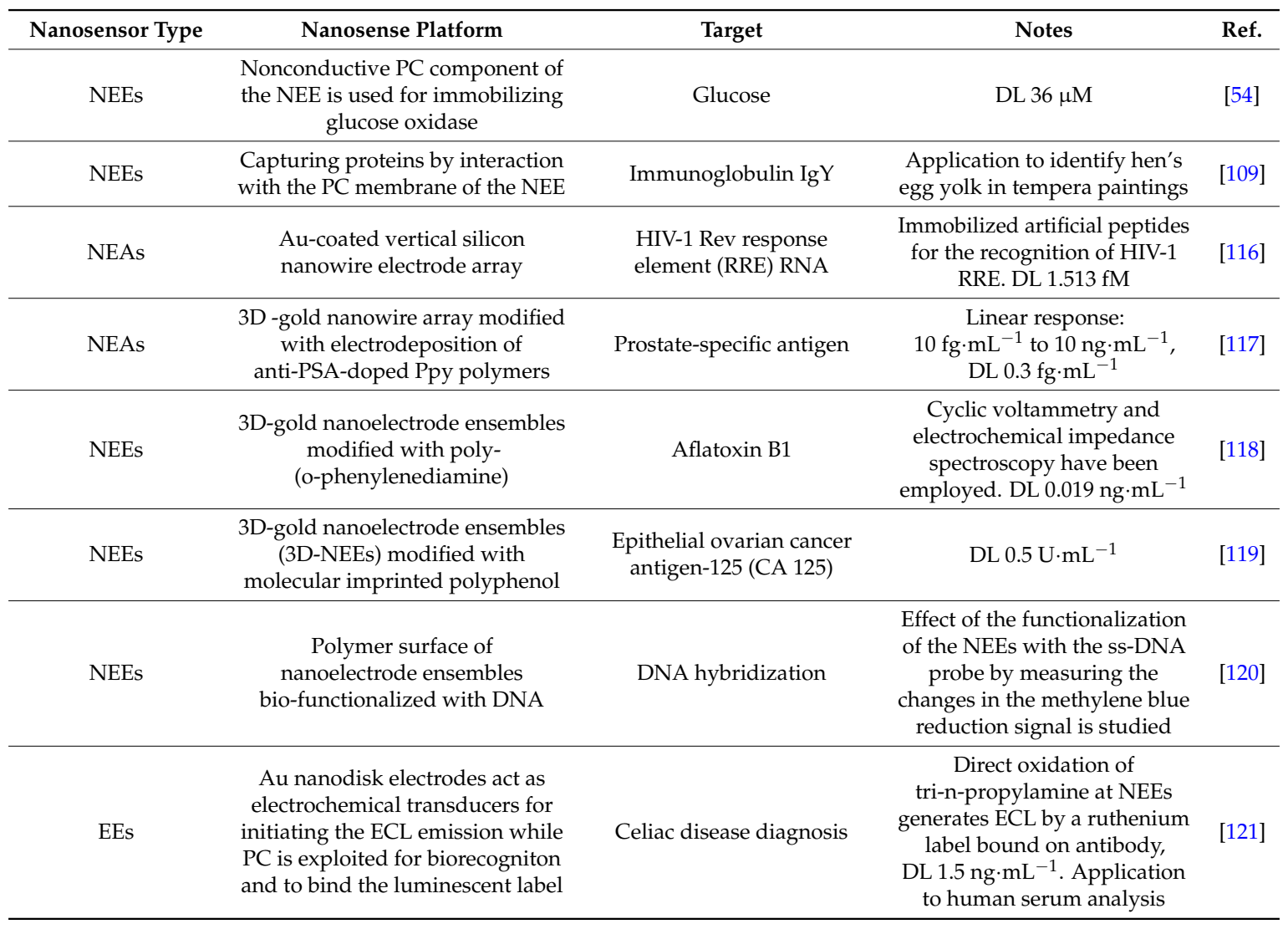

Table 3. Articles published in the years 2012-2016, dealing with biosensing application of arrays of nanochannels, nanopores and nanotubes.

\begin{tabular}{|c|c|c|c|c|}
\hline Nanosensor Type & Nanosense Platform & Target & Notes & Ref. \\
\hline Nano channel & $\begin{array}{c}\text { Inner walls of the PAA } \\
\text { nanochannels are functionalized } \\
\text { with GOx; a bottom Au layer acts } \\
\text { as working electrode. }\end{array}$ & $\begin{array}{l}\text { Enzymatic reactivity of } \\
\text { glucose oxidase }\end{array}$ & $\begin{array}{l}\text { Activity and stability of the } \\
\text { glucose oxidase immobilized } \\
\text { in the nanochannels is } \\
\text { largely enhanced }\end{array}$ & [123] \\
\hline Nano channel & $\begin{array}{l}\text { Functionalization of PAA } \\
\text { nanochannels with DNA }\end{array}$ & $\begin{array}{l}\text { To monitor online } \\
\text { immunological reactions } \\
\text { and biosensing process in } \\
\text { the nanochannels }\end{array}$ & $\begin{array}{l}\text { Study to evaluate the speed } \\
\text { of antibody and the } \\
\text { immunological reaction } \\
\text { progress in nanochannels }\end{array}$ & [124] \\
\hline Nanowell array & $\begin{array}{l}\text { Integration of PAA membranes on } \\
\text { printed circuit board platforms }\end{array}$ & $\begin{array}{l}\text { Prostate-specific } \\
\text { antigen (PSA) }\end{array}$ & $\begin{array}{l}\text { PSA detection between } \\
0.01 \text { and } 1000 \mathrm{ng} \cdot \mathrm{mL}^{-1}\end{array}$ & [125] \\
\hline Nanotube array & $\begin{array}{c}\text { Electrodepositing } \mathrm{Au} \\
\text { nanoparticles on the inner wall } \\
\text { of } \mathrm{TiO}_{2} \text { nanotube arrays }\end{array}$ & $\begin{array}{l}\text { Cytochrome P450 2C9 } \\
\text { enzyme as a model } \\
\text { enzyme and tolbutamide } \\
\text { as a model substrate }\end{array}$ & $\begin{array}{l}\text { Excellent enzymatic activity, } \\
\text { high affinity, and metabolic } \\
\text { efficiency for tolbutamide }\end{array}$ & [126] \\
\hline
\end{tabular}

Among these recent advances, a particularly novel research line focuses on the study of array of nanochannels for performing the real-time monitoring of the enzyme reaction kinetics in confined nanospace (see Table 3). Concerning nanowells and nanochannels electrodes, different strategies for their fabrication were proposed. The most widely used material has been porous anodic alumina 
(PAA). PAA membranes are indeed characterized by tunable nanopore diameter in highly ordered array, easy surface modification, good mechanical stability and biocompatibility. A PAA nanowell based disposable biosensor for detecting PSA in human serum has been fabricated and tested [125]. It was designed by integrating nanoporous alumina membranes onto printed circuit board platforms, resulting in arrays of high-density nanowells, with gold electrodes at the bottom of the wells (Figure 14).

The sensor showed a rapid response time $(<3 \mathrm{~min})$ with a detection sensitivity in the $\mathrm{pg} \cdot \mathrm{mL}^{-1}$ range, for samples of small volume $(\sim 100 \mu \mathrm{L}$ per test).A nanochannel-enzyme system was prepared by covalently linking glucose oxidase (GOD) on the inner wall of the nanochannels of a PAA membrane [123]. An Au disk was attached at the end of the PAA membrane and used as working electrode for the detection of $\mathrm{H}_{2} \mathrm{O}_{2}$ generated by the enzymatic reaction.

Continuing on this research line, Liu et al. proposed a nanochannel-based electrochemical reactor and a model to describe the kinetics of immunological reaction within nanochannels [124] Attention was put in investigating the role of steric and electrostatic effects on the flow parameters.

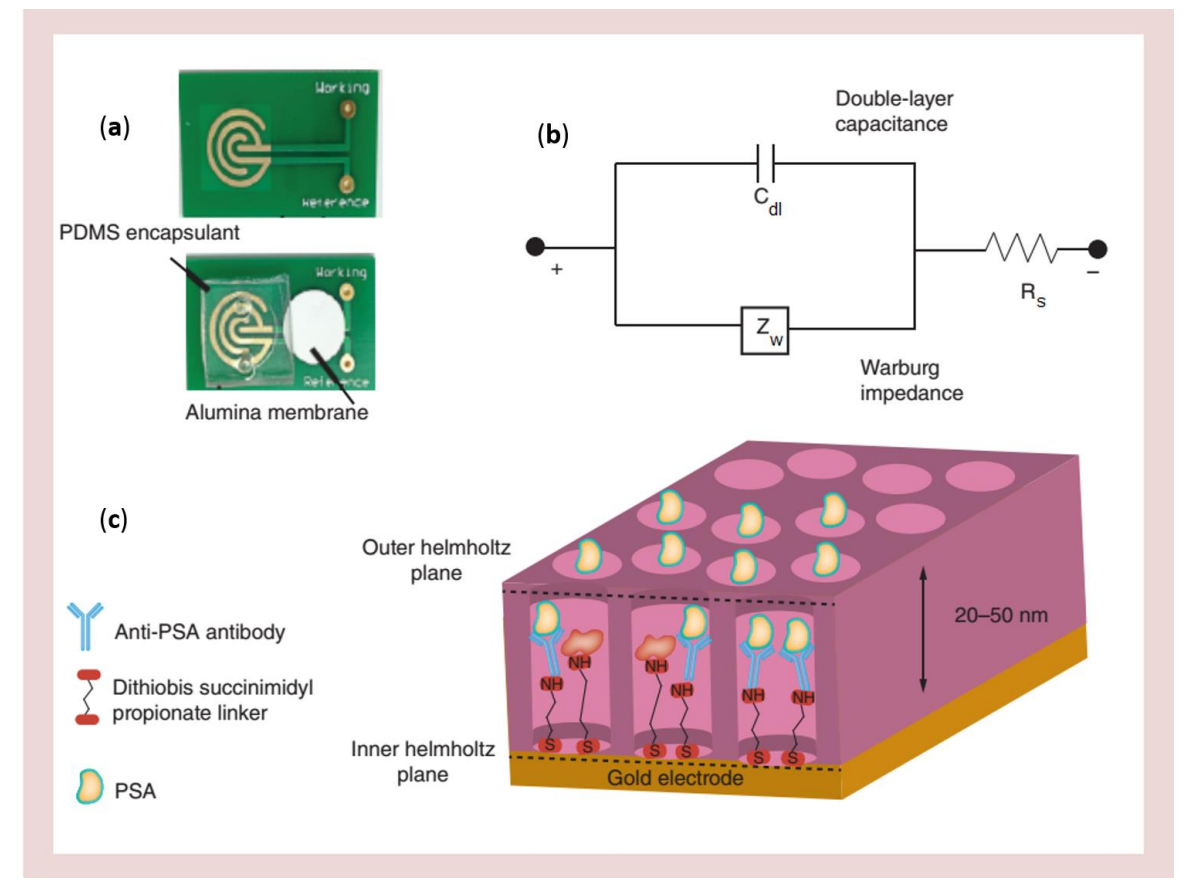

Figure 14. Electrical nanowell biosensor design, assembly and operation. Sensor device and operation (a) optical micrograph showing the gold microelectrodes, PDMS encapsulant and nanoporous alumina membrane (b) modified Randles equivalent circuit for label-free non-faradaic impedance spectroscopy and (c) schematic representation of binding events at the electrical double layer. PDMS: Polydimethyl siloxane; PSA: Prostate-specific antigen (reprinted with permission from [125]).

A new approach to prepare nanopore arrays by alternate current (AC) electrodeposition of gold nanowires in PAA was proposed by $\mathrm{Li}$ et al. [127]. It was demonstrated that the voltammetric limiting current can be tuned by controlling the surface charge on the PAA walls by changing the solution $\mathrm{pH}$.

A nanotube array enzymatic reactor was produced by electrostatically adsorbing cytochrome P450 2C9 enzyme (CYP2C9) on the inner wall of $\mathrm{TiO}_{2}$ nanotube arrays (TNAs) [126]. Different dimensions of TNAs were fabricated by controlling anodization potential or time. Au nanoparticles were deposited on the inner wall of TNAs to lower the electrical resistance. The CYP2C9 enzyme confined in the TNA exhibited excellent enzymatic activity, high affinity, and metabolic efficiency toward the substrate of tolbutamide with high sensitivity.

Future developments of such nanochannel-enzyme systems can be the design of future biosensors and enzyme reactors characterized by significantly high sensitivity and analytical efficiency. 


\section{Conclusions and Prospects}

Nanoelectrode arrays and ensembles are opening new applicative prospects to the development of highly sensitive, selective and miniaturized biosensing devices. On one side, the template synthesis has made widely accessible the preparation of electrode systems with critical dimensions in the domain of nanometer. The use of nanoporous templates constitutes indeed an attractive and practical methodology for the preparation of a variety of ensembles of nanomaterials such as nanodisks, nanowires, nanotubes but also nanopores, nanowells or other hierarchically engineered nanostructures. These nanomaterials show particular and advantageous performances in the electroanalytical and biosensing fields. On the other hand, more sophisticated and complex procedures such as electron-beam or ion-beam lithography, allow the preparation of highly ordered arrays with perfectly controlled geometries. Both arrays and ensembles can be turned into 3D-nanostructures by using suitable nanofabrication procedures such as chemical or physical etching.

For electroanalytical and sensing applications both NEEs/NEAs show dramatically enhanced signal-to-background ratios with respect to any other electrode system, together with the possibility to measure rather easily very fast charge transfer kinetic constant of interest for fundamental studies. However, a deep knowledge of the characteristics of diffusion and charge transfer processes at bio-nanostructured surfaces is required to obtain the maximum in biosensing performances from these devices. For instance, the use of too densely packed arrays of nanoelectrodes could hamper some of the advantages of NEEs/NEAs (e.g., highly improved S/N ratios). Moreover, wise users should take into account that the high sensitivity of these devices to the electron transfer kinetics make their analytical application advantageous mainly for very fast redox couples.

For biosensing purposes, the smart use of the morphological characteristics and the composite structure of the arrays allow to maximize their biorecognition performances. This is the case when the large surface of 3D arrays is used to immobilize large amounts of biorecognition molecules. An interesting alternative, which exploits and keep at the maximum the high $\mathrm{S} / \mathrm{N}$ ratio typical of NEEs/NEAs, is offered by the capability to functionalize the polymer surface which separates the nanoelectrodes in 2D arrays.

Practical applications for biosensing and diagnostic aims in real samples are growing quickly. To overcome problems of fouling, one can indeed protect the nanoelectrode surface by the clever use of thiols as anti-fouling agents [8]. New prospects will be opened by combining a deeper understanding of the mechanisms (and their modeling) which rule mass transport, (bio)chemical kinetics and electron transfer at NEEs/NEAs together with the development of more refined nanofabrication procedures.

From a technical development viewpoint, multiplexed analysis of different analytes will be possible by further developments in the preparation and application of individually addressable arrays of nanoelectrodes, as described in some frontier papers [94,128-131].

Author Contributions: N.K. performed bibliographic research, wrote the tables and part of the text, and organized all the references. L.M.M. wrote part of the text and took care of the figures and revised the final version. P.U. conceived and designed the review; wrote part of the text and corrected the final version.

Conflicts of Interest: The authors declare no conflict of interest.

\section{References}

1. Martin, C.R.; Mitchell, D.T. Template-synthesed nanomaterials in electrochemistry. In Electroanalytical Chemistry; Bard, A.J., Rubinstein, I., Eds.; Marcel Dekker: New York, NY, USA, 1999; Volume 21, pp. 1-74.

2. Ugo, P.; Moretto, L.M.; Vezzà, F. Ionomer-coated electrodes and nanoelectrode ensembles as electrochemical environmental sensors: Recent advances and prospects. Chem. Phys. Chem. 2002, 3, 917-925. [CrossRef]

3. Arrigan, D.W.M. Nanoelectrodes, nanoelectrode arrays and their application. Analyst 2004, 129, 1157-1165. [CrossRef] [PubMed]

4. Ongaro, M.; Ugo, P. Bioelectroanalysis with nanoelectrode ensembles and arrays. Anal. Bioanal. Chem. 2013, 405, 3715-3721. [CrossRef] [PubMed] 
5. De Leo, M.; Kuhn, A.; Ugo, P. 3D-ensembles of gold nanowires: Preparation, characterization and electroanalytical peculiarities. Electroanalysis 2007, 19, 227-236. [CrossRef]

6. Heim, M.; Reculusa, S.; Ravaine, S.; Kuhn, A. Engineering of complex macroporous materials through controlled electrodeposition in colloidal superstructures. Adv. Funct. Mater. 2012, 22, 538-545. [CrossRef]

7. Godino, N.; Borrise, X.; Munoz, F.X.; del Campo, F.J.; Compton, R.G. Mass transport to nanoelectrode arrays and limitations of the diffusion domain approach: Theory and experiment. J. Phys. Chem. C 2009, 113, 11119-11125. [CrossRef]

8. Silvestrini, M.; Schiavuta, P.; Scopece, P.; Pecchielan, G.; Moretto, L.M.; Ugo, P. Modification of nanoelectrode ensembles by thiols and disulfides to prevent non specific adsorption of proteins. Electrochim. Acta 2011, 56, 7718-7724. [CrossRef]

9. Pozzi Mucelli, S.; Zamuner, M.; Tormen, M.; Stanta, G.; Ugo, P. Nanoelectrode ensembles as recognition platform for electrochemical immunosensors. Biosens. Bioelectron. 2008, 23, 1900-1903. [CrossRef] [PubMed]

10. Fayazfar, H.; Afshar, A.; Dolati, A. Electrodeposition of various Au nanostructures on aligned carbon nanotubes as highly sensitive nanoelectrode ensembles. J. Mater. Eng. Perform. 2015, 24, 2005-2015. [CrossRef]

11. Mohamed, N.M.; Irshad, M.I.; Abdullah, M.Z.; Saheed, M.S.M. Novel growth of carbon nanotubes on nickel nanowires. Diamond Relat. Mater. 2016, 65, 59-64. [CrossRef]

12. Malhotra, R.; Patel, V.; Vaqué, J.P.; Gutkind, J.S.; Rusling, J.F. Ultrasensitive electrochemical immunosensor for oral cancer biomarker IL-6 using carbon nanotube forest electrodes and multilabel amplification. Anal. Chem. 2010, 82, 3118-3123. [CrossRef] [PubMed]

13. Malhotra, R.; Papadimitrakopoulos, F.; Rusling, J.F. Sequential layer analysis of protein immunosensors based on single wall carbon nanotube forests. Langmuir 2010, 26, 15050-15056. [CrossRef] [PubMed]

14. Gholizadeh, A.; Shahrokhian, S.; Iraji zad, A.; Mohajerzadeh, S.; Vosoughi, M.; Darbari, S.; Koohsorkhi, J.; Mehran, M. Fabrication of sensitive glutamate biosensor based on vertically aligned CNT nanoelectrode array and investigating the effect of CNTs density on the electrode performance. Anal. Chem. 2012, 84, 5932-5938. [CrossRef] [PubMed]

15. Periyakaruppan, A.; Gandhiraman, R.P.; Meyyappan, M.; Koehne, J.E. Label-free detection of cardiac troponin I using carbon nanofiber based nanoelectrode arrays. Anal. Chem. 2013, 85, 3858-3863. [CrossRef] [PubMed]

16. Hernandez-Rivera, M.; Zaibaq, N.G.; Wilson, L.J. Toward carbon nanotube-based imaging agents for the clinic. Biomaterials 2016, 101, 229-240. [CrossRef] [PubMed]

17. Sajid, M.I.; Jamshaid, U.; Jamshaid, T.; Zafar, N.; Fessi, H.; Elaissari, A. Carbon nanotubes from synthesis to in vivo biomedical applications. Int. J. Pharm. 2016, 501, 278-299. [CrossRef] [PubMed]

18. Yan, Y.; Miao, J.; Yang, Z.; Xiao, F.X.; Yang, H.B.; Liu, B.; Yang, Y. Carbon nanotube catalysts: Recent advances in synthesis, characterization and applications. Chem. Soc. Rev. 2015, 44, 3295-3346. [CrossRef] [PubMed]

19. Tîlmaciu, C.M.; Morris, M.C. Carbon nanotube biosensors. Front Chem. 2015, 3, 59-79. [CrossRef] [PubMed]

20. Menon, V.P.; Martin, C.R. Fabrication and evaluation of nanoelectrode ensembles. Anal. Chem. 1995, 67, 1920-1928. [CrossRef]

21. Possin, G.E. A method for forming very small diameter wires. Rev. Sci. Instrum. 1970, 41, 772-774. [CrossRef]

22. Williams, W.D.; Giordano, N. Fabrication of $80 \mathrm{~A}^{\circ}$ metal wires. Rev. Sci. Instrum. 1984, 55, 410-412. [CrossRef]

23. Routkevitch, D.; Bigioni, T.; Moskovits, M.; Xu, J.M. Electrochemical fabrication of CdS nanowire arrays in porous anodic aluminum oxide template. J. Phys. Chem. C 1996, 100, 14037-14047. [CrossRef]

24. Schoenberger, C.; van der Zande, B.M.I.; Fokkink, L.G.J.; Henny, M.; Schmid, C.; Kruger, M.; Bachtold, A.; Huber, R.; Birk, H.; Staufer, U. Template synthesis of nanowires in porous polycarbonate membranes: Electrochemistry and morphology. J. Phys. Chem. B 1997, 101, 5497-5505. [CrossRef]

25. Penner, R.M.; Martin, C.R. Preparation and electrochemical characterization of ultramicroelectrode ensembles. Anal. Chem. 1987, 59, 2625-2630. [CrossRef]

26. De Leo, M.; Pereira, F.C.; Moretto, L.M.; Scopece, P.; Polizzi, S.; Ugo, P. Towards a better understanding of gold electroless deposition in track-etched templates. Chem. Mater. 2007, 19, 5955-5964. [CrossRef]

27. Gilliam, R.J.; Thorpe, S.J.; Kirk, D.J.W. A nucleation and growth study of gold nanowires and nanotubes in polymeric membranes. Appl. Electrochem. 2006, 37, 233-239. [CrossRef] 
28. Konishi, Y.; Motoyama, M.; Matsushima, H.; Fukunaka, Y.; Ishii, R.; Ito, Y. Electrodeposition of Cu nanowire arrays with a template. J. Electroanal. Chem. 2003, 559, 149-153. [CrossRef]

29. Stortini, A.M.; Moretto, L.M.; Mardegan, A.; Ongaro, M.; Ugo, P. Arrays of copper nanowire electrodes: Preparation, characterization and application as nitrate sensor. Sens. Actuators B Chem. 2015, 207, 186-192. [CrossRef]

30. Gambirasi, A.; Cattarin, S.; Musiani, M.; Vázquez-Gómez, L.; Verlato, E. Direct electrodeposition of metal nanowires on electrode surface. Electrochim. Acta 2011, 56, 8582-8588. [CrossRef]

31. Motoyama, M.; Fukunaka, Y.; Sakka, T.; Ogata, Y.H.; Kikuchi, S. Electrochemical processing of Cu and Ni nanowire arrays. J. Electroanal. Chem. 2005, 584, 84-91. [CrossRef]

32. Piraux, L.; Duboix, S.; Champagne, S. Template synthesis of nanoscale materials using the membrane porosity. Nucl. Instrum. Methods Phys. Res. Sect. B 1997, 131, 357-363. [CrossRef]

33. Chiriac, H.; Moga, A.E.; Urse, M.; Ovari, T.A. Preparation and magnetic properties of electrodeposited magnetic nanowires. Sens. Actuators A Phys. 2003, 106, 348-351. [CrossRef]

34. Pirota, K.R.; Navas, D.; Hernandez-Vélez, M.; Nielsch, K.; Vasquez, M. Novel magnetic materials prepared by electrodeposition techniques: Arrays of nanowires and multi-layered microwires. J. Alloy Compd. 2004, 369, 18-26. [CrossRef]

35. Platt, M.; Dryfeand, R.A.W.; Robaerts, E.P.L. Structural and electrochemical characterisation of Pt and Pd nanoparticles electrodeposited at the liquid/liquid interface. Electrochim. Acta 2004, 49, 3937-3945. [CrossRef]

36. Prieto, A.L.; Sander, M.S.; Gonzalez, M.S.M.; Gronsky, R.; Sands, T.; Stacy, A.M. Electrodeposition of ordered $\mathrm{Bi}_{2} \mathrm{Te}_{3}$ nanowire arrays. J. Am. Chem. Soc. 2001, 123, 7160-7161. [CrossRef] [PubMed]

37. Bograchev, D.A.; Volgin, V.M.; Davydov, A.D. Simulation of inhomogeneous pores filling in template electrodeposition of ordered metal nanowire arrays. Electrochim. Acta 2013, 112, 279-286. [CrossRef]

38. Bograchev, D.A.; Volgin, V.M.; Davydov, A.D. Modeling of metal electrodeposition in the pores of anodic aluminum oxide. Russ. J. Electrochem. 2015, 51, 799-806. [CrossRef]

39. Bograchev, D.A.; Volgin, V.M.; Davydov, A.D. Simple model of mass transfer in template synthesis of metal ordered nanowire arrays. Electrochim. Acta 2013, 96, 1-7. [CrossRef]

40. Volgin, V.M.; Davydov, A.D. Mass-transfer problems in the electrochemical systems. Russ. J. Electrochem. 2012, 48, 565-569. [CrossRef]

41. Yu, C.; Xie, Y.; Xu, T.; Chen, Y.; Li, X.; Li, W.; Liu, B.; Zhang, X. Growth kinetics of nickel crystals in nanopores. Crystal Growth Des. 2009, 9, 3840-3843. [CrossRef]

42. Philippe, L.; Kacem, N.; Michler, J. Electrochemical deposition of metals inside high aspect ratio nanoelectrode array: Analytical current expression and multidimensional kinetic model for cobalt nanostructure synthesis. J. Phys. Chem. C 2007, 111, 5229-5235. [CrossRef]

43. Paunovic, M.; Schlesinger, M. Modern Electroplating; Wiley: New York, NY, USA, 2000.

44. Pereira, F.C.; Moretto, L.M.; De Leo, M.; Boldrin Zanoni, M.V.; Ugo, P. Gold nanoelectrode ensembles for direct trace electroanalysis of iodide. Anal. Chim. Acta 2006, 575, 16-24. [CrossRef] [PubMed]

45. Jirage, K.B.; Hulteen, J.C.; Martin, C.R. Nanotubule-based molecular-filtration membranes. Science 1997, 278, 655-658. [CrossRef]

46. Hulteen, J.C.; Jirage, K.B.; Martin, C.R. Introducing chemical transport selectivity into gold nanotubule membranes. J. Am. Chem. Soc. 1998, 120, 6603-6604. [CrossRef]

47. Jirage, K.B.; Hulteen, J.C.; Martin, C.R. Effects of thiol chemisorptions on the transport properties of gold nanotubule membranes. Anal. Chem. 1999, 71, 4913-4918. [CrossRef] [PubMed]

48. Kobayashi, Y.; Martin, C.R. Highly-sensitive methods for electroanalytical chemistry based on nanotubule membranes. Anal. Chem. 1999, 71, 3665-3672. [CrossRef] [PubMed]

49. Bercu, B.; Enculescu, I.; Spohr, R. Copper tubes prepared by electroless deposition in ion track templates. Nucl. Instrum. Methods Phys. Res. Sect. B 2004, 225, 497-502. [CrossRef]

50. Dryfe, R.A.W.; Simm, A.O.; Kralj, B. Electroless deposition of palladium at bare and templated liquid/liquid interfaces. J. Am. Chem. Soc. 2003, 125, 13014-13015. [CrossRef] [PubMed]

51. Tai, Y.L.; Teng, H. Template synthesis and electrochemical characterization of nickel based tubule electrode arrays. Chem. Mater. 2004, 16, 338-342. [CrossRef]

52. Ugo, P.; Moretto, L.M. Template deposition of metals. In Handbook of Electrochemistry; Zoski, C.G., Ed.; Elsevier: Amsterdam, The Netherlands, 2007; pp. 678-709. 
53. Moretto, L.M.; Pepe, N.; Ugo, P. Voltammetry of redox analytes at trace concentrations with nanoelectrodes ensembles. Talanta 2004, 62, 1055-1060. [CrossRef] [PubMed]

54. Habtamu, H.B.; Ugo, P. Miniaturized enzymatic biosensor via biofunctionalization of the insulator of nanoelectrode ensembles. Electroanalysis 2015, 27, 2187-2193. [CrossRef]

55. Ongaro, M.; Gambirasi, A.; Favaro, M.; Ugo, P. Electrochemical synthesis and characterization of hierarchically branched $\mathrm{ZnO}$ nanostructures on ensembles of gold nanowires. Electrochim. Acta 2012, 78, 539-546. [CrossRef]

56. Ongaro, M.; Gambirasi, A.; Ugo, P. Closed bipolar electrochemistry for the low-potential asymmetrical functionalization of micro- and nanowires. ChemElectroChem 2016, 3, 450-456. [CrossRef]

57. Bard, A.J.; Faulkner, L. Electrochemical Methods; VCH: Weinheim, Germany, 2000.

58. Dickinson, E.J.F.; Compton, R.G. Diffuse double layer at nanoelectrodes. Phys. Chem. Lett. C 2009, 113, 17585-17589. [CrossRef]

59. Chen, S.; Liu, Y. Electrochemistry at nanometer-sized electrodes. Phys. Chem. Chem. Phys. 2014, 16, 635-652. [CrossRef] [PubMed]

60. Henstridge, M.C.; Compton, R.G. Mass transport to micro- and nanoelectrodes and their arrays: A review. Chem. Rec. 2011, 12, 63-71. [CrossRef] [PubMed]

61. Lee, H.J.; Beriet, C.; Ferrigno, R.; Girault, H.H. Cyclic voltammetry at a regular microdisc electrode array. J. Electroanal. Chem. 2001, 502, 138-145. [CrossRef]

62. Hulteen, J.C.; Menon, V.P.; Martin, C.R. Template preparation of nanoelectrode ensembles achieving the 'pure-radial' electrochemical response limiting case. J. Chem. Soc. Faraday Trans. 1996, 92, 4029-4032. [CrossRef]

63. Cheng, J.F.; Whitley, L.D.; Martin, C.R. Ultramicroelectrode ensembles. Comparison of experimental and theoretical responses and evaluation of electroanalytical detection limits. Anal. Chem. 1989, 61, 762-766. [CrossRef]

64. Guo, J.; Lindner, E. Cyclic voltammograms at coplanar and shallow recessed microdisk electrode arrays: Guidelines for design and experiment. Anal. Chem. 2009, 81, 130-138. [CrossRef] [PubMed]

65. Davies, T.J.; Compton, R.G. The cyclic and linear sweep voltammetry of regular and random arrays of microdisc electrodes: Theory. J. Electroanal. Chem. 2005, 585, 63-82. [CrossRef]

66. Huang, X.J.; O'Mahony, A.M.; Compton, R.G. Microelectrode arrays for electrochemistry: Approaches to fabrication. Small 2009, 7, 776-788. [CrossRef] [PubMed]

67. Amatore, C.; Oleinik, A.I.; Svir, I. Numerical simulation of diffusion processes at recessed disk microelectrode arrays using the quasi-conformal mapping approach. Anal. Chem. 2009, 81, 4397-4405. [CrossRef] [PubMed]

68. Moretto, L.M.; Tormen, M.; De Leo, M.; Carpentiero, A.; Ugo, P. Polycarbonate-based ordered arrays of electrochemical nanoelectrodes obtained by e-beam lithography. Nanotechnology 2011, 22, 185305-185311. [CrossRef] [PubMed]

69. Sliusarenko, O.; Oleinick, A.; Svir, I.; Amatore, C. Development and validation of an analytical model for predicting chronoamperometric responses of random arrays of micro- and nanodisk electrodes. ChemElectroChem 2015, 2, 1279-1291. [CrossRef]

70. Ugo, P.; Moretto, L.M.; De Leo, M.; Doherty, A.P.; Vallese, C.; Pentlavalli, S. Diffusion regimes at nanoelectrode ensembles in different ionic liquids. Electrochim. Acta 2010, 55, 2865-2872. [CrossRef]

71. Ugo, P.; Moretto, L.M.; Vezzà, F. Ionomer-coated electrodes and nanoelectrode ensembles as electrochemical environmental sensors: Recent advances and prospects. In Sensors Update; Baltes, H., Fedder, G.K., Korvink, J.G., Eds.; Wiley-VCH: Weinheim, Germany, 2003; Volume 12, pp. 121-140.

72. Ugo, P.; Moretto, L.M.; Bellomi, S.; Menon, V.P.; Martin, C.R. Ion exchange voltammetry at polymer film coated nanoelectrode ensembles. Anal. Chem. 1996, 68, 4160-4165. [CrossRef] [PubMed]

73. Brunetti, B.; Ugo, P.; Moretto, L.M.; Martin, C.R. Electrochemistry of phenothiazine and methylviologen biosensor electrontransfer mediators at nanoelectrode ensembles. J. Electroanal. Chem. 2000, 491, 166-174. [CrossRef]

74. Errachid, A.; Mills, C.A.; Pla-Roca, M.; Lopez, M.J.; Villanueva, G.; Bausells, J.; Crespo, E.; Teixidor, F.; Samitier, J. Focused ion beam production of nanoelectrode arrays. Mater. Sci. Eng. C 2008, 28, 777-780. [CrossRef] 
75. Lanyon, Y.H.; De Marzi, G.; Watson, Y.E.; Quinn, A.J.; Gleeson, J.P.; Redmond, G.; Arrigan, D.W.M. Fabrication of nanopore array electrodes by focused ion beam milling. Anal. Chem. 2007, 79, 3048-3055. [CrossRef] [PubMed]

76. Sandison, M.E.; Cooper, J.M. Nanofabrication of electrode arrays by electron-beam and nanoimprint lithographies. Lab Chip 2006, 6, 1020-1025. [CrossRef] [PubMed]

77. Losilia, N.S.; Martinez, J.; Garcia, R. Large area nanoscale patterning of silicon surfaces by parallel local oxidation. Nanotechnology 2009, 20, 475304-475308. [CrossRef] [PubMed]

78. Losilia, N.S.; Oxtoby, N.S.; Martinez, J.; Garcia, F.; Garcia, R.; Mas-Torrent, M.; Vecciana, J.; Rovia, C. Sub-50 nm positioning of organic compounds onto silicon oxide patterns fabricated by local oxidation nanolithography. Nanotechnology 2008, 19, 455308-455313. [CrossRef] [PubMed]

79. Albonetti, C.; Martinez, J.; Losilia, N.S.; Greco, P.; Cavallini, M.; Borgatti, F.; Montecchi, M.; Pasquali, L.; Garcia, R.; Biscarini, F. Parallel-local anodic oxidation of silicon surfaces by soft stamps. Nanotechnology 2008, 19, 435303-435311. [CrossRef] [PubMed]

80. Zamuner, M.; Pozzi Mucelli, S.; Tormen, M.; Stanta, G.; Ugo, P. Electrochemical nanobiosensors and protein detection. Eur. J. Nanomed. 2008, 1, 33-36. [CrossRef]

81. Yang, N.; Foord, J.S.; Jiang, X. Diamond electrochemistry at the nanoscale: A review. Carbon 2016, 99, 90-110. [CrossRef]

82. Xiao, L.; Streeter, I.; Wildgoose, G.G.; Compton, R.G. Fabricating random arrays of boron doped diamond nano-disc electrodes: Towards achieving maximum faradaic current with minimum capacitive charging. Sens. Actuators B Chem. 2008, 33, 118-127. [CrossRef]

83. Hees, J.; Hoffmann, R.; Kriele, A.; Smirnov, W.; Obloh, H.; Glorer, K.; Raynor, B.; Driad, R.; Yang, N.; Williams, O.A.; et al. Nanocrystalline diamond nanoelectrode arrays and ensembles. ACS Nano 2011, 5, 3339-3346. [CrossRef] [PubMed]

84. Virgilio, F.; Prasciolu, M.; Ugo, P.; Tormen, M. Development of electrochemical biosensors by e-beam lithography for medical diagnostics. Microelectron. Eng. 2013, 111, 320-324. [CrossRef]

85. Liu, Y.; Holzinger, A.; Knittel, P.; Poltorak, L.; Gamero-Quijano, A.; Rickard, W.D.A.; Walcarius, A.; Herzog, G.; Kranz, C.; Arrigan, D.W.M. Visualization of diffusion within nanoarrays. Anal. Chem. 2016, 88, 6689-6695. [CrossRef] [PubMed]

86. Dincer, C.; Laubender, E.; Hees, J.; Nebel, C.E.; Urban, G.; Heinze, J. SECM detection of single boron doped diamond nanodes and nanoelectrode arrays using phase-operated shear force technique. Electrochem. Commun. 2012, 24, 123-127. [CrossRef]

87. Hees, J.; Hoffmann, R.; Yang, N.; Nebel, C.E. Diamond nanoelectrode arrays for the detection of surface sensitive adsorption. Chem. Eur. J. 2013, 19, 11287-11292. [CrossRef] [PubMed]

88. Sentic, M.; Virgilio, F.; Zanut, A.; Manojlovic, D.; Arbault, S.; Tormen, M.; Sojic, N.; Ugo, P. Microscopic imaging and tuning of electrogenerated chemiluminescence with boron-doped diamond nanoelectrode arrays. Anal. Bioanal. Chem. 2016, 408, 7085-7094. [CrossRef] [PubMed]

89. Amatore, C.; Saveant, J.M.; Tessier, D. Charge transfer at partially blocked surfaces. A model for the case of microscopic active and inactive sites. J. Electroanal. Chem. Interfacial Electrochem. 1983, 147, 39-51. [CrossRef]

90. Greef, R.; Pea, R.; Peter, L.M.; Pletcher, D.; Robinson, J. Instrumental Methods in Electrochemistry; Ellis Horwood Ltd.: Chester, UK, 1985.

91. Nicholson, R.S. Theory and application of cyclic voltammetry for measurement of electrode reaction kinetics. Anal. Chem. 1965, 37, 1351-1355. [CrossRef]

92. Yu, S.; Li, N.; Wharton, J.; Martin, C.R. Nano wheat fields prepared by plasma-etching gold nanowire-containing membranes. Nano Lett. 2003, 3, 815-818. [CrossRef]

93. Gasparac, R.; Taft, B.J.; Lapierre-Devlin, M.A.; Lazareck, A.D.; Xu, J.M.; Kelley, S.O. Ultrasensitive electrocatalytic DNA detection at two- and three-dimensional nanoelectrodes. J. Am. Chem. Soc. 2004, 126, 12270-12271. [CrossRef] [PubMed]

94. Zoski, C.G.; Yang, N. Addressable nanoelectrode membrane arrays: Fabrication and steady-state behavior. Anal. Chem. 2007, 79, 1474-1484. [CrossRef] [PubMed]

95. Ugo, P.; Moretto, L.M.; Scrosati, B. Electrodes I nanoelectrodes. In Encyclopedia of Electrochemical Power Sources; Garche, J., Dyer, C., Moseley, P., Ogumi, Z., Rand, D., Scrosati, B., Eds.; Elsevier: Amsterdam, The Netherlands, 2009; Volume 2, pp. 92-102. 
96. Krishnamoorthy, K.; Zoski, C.G. Fabrication of 3D gold nanoelectrode ensembles by chemical etching. Anal. Chem. 2005, 77, 5068-5071. [CrossRef] [PubMed]

97. Cao, L.; Yan, P.; Sun, K.; Kirk, D.W. Tailor-made gold brush nanoelectrode ensembles modified with L-cysteine for the detection of daunorubicine. Electrochim. Acta 2008, 53, 8144-8148. [CrossRef]

98. Cao, L.; Yan, P.; Sun, K.; Kirk, D.W. Gold 3D brush nanoelectrode ensembles with enlarged active area for the direct voltammetry of daunorubicin. Electroanalysis 2009, 21, 1183-1188. [CrossRef]

99. Moretto, L.M.; Panero, S.; Scrosati, B.; Ugo, P. Templated ensembles of nanoelectrodes. In Handbook of Electrochemical Nanotechnology; Lin, Y., Nalwa, H.S., Eds.; American Scientific: Stevenson Ranch, CA, USA, 2009; Volume 1, pp. 87-105.

100. Sliusarenko, O.; Oleinick, A.; Svir, I.; Amatore, C. Validating a central approximation in theories of regular electrode electrochemical arrays of various common geometries. Electroanalysis 2015, 27, 980-991. [CrossRef]

101. Ugo, P.; Moretto, L.M.; Ongaro, M.; Scrosati, B. Electrodes I Nanoelectrodes; Elsevier: Waltham, MA, USA, 2015.

102. Ugo, P.; Moretto, L.M.; Silvestrini, M.; Pereira, F.C. Nanoelectrode ensembles for the direct voltammetric determination of trace iodide in water. Int. J. Environ. Anal. Chem. 2010, 90, 747-759. [CrossRef]

103. Ugo, P.; Pepe, N.; Moretto, L.M.; Battagliarin, M. Direct voltammetry of cytochrome c at trace concentrations with nanoelectrode ensembles. J. Electroanal. Chem. 2003, 560, 51-58. [CrossRef]

104. Mardegan, A.; Scopece, P.; Lamberti, F.; Meneghetti, M.; Moretto, L.M.; Ugo, P. Electroanalysis of trace inorganic arsenic with gold nanoelectrode ensembles. Electroanalysis 2012, 24, 798-806. [CrossRef]

105. Mardegan, A.; Borgo, S.D.; Scopece, P.; Moretto, L.M.; Hočevar, S.B.; Ugo, P. Bismuth modified gold nanoelectrode ensemble for stripping voltammetric determination of lead. Electrochem. Commun. 2012, 24, 28-31. [CrossRef]

106. Viswanathan, S.; Rani, C.; Delerue-Matos, C. Ultrasensitive detection of ovarian cancer marker using immunoliposomes and gold nanoelectrodes. Anal. Chim. Acta 2012, 726, 79-84. [CrossRef] [PubMed]

107. Silvestrini, M.; Fruk, L.; Ugo, P. Functionalized ensembles of nanoelectrodes as affinity biosensors for DNA hybridization detection. Biosens. Bioelectron. 2013, 40, 265-270. [CrossRef] [PubMed]

108. Fruk, L.; Müller, J.; Weber, G.; Narvaez, A.; Dominguez, E.; Niemeyer, C.M. DNA-directed immobilization of horseradish peroxidase-DNA conjugates on microelectrode arrays: Towards electrochemical screening of enzyme libraries. Chem. Eur. J. 2007, 13, 5223-5231. [CrossRef] [PubMed]

109. Bottari, F.; Oliveri, P.; Ugo, P. Electrochemical immunosensor based on ensemble of nanoelectrodes for immunoglobulin IgY detection: Application to identify hen's egg yolk in tempera paintings. Biosens. Bioelectron. 2014, 52, 403-410. [CrossRef] [PubMed]

110. Mollamahale, Y.B.; Ghorbani, M.; Ghalkhani, M.; Vossoughi, M.; Dolati, A. Highly sensitive 3D gold nanotube ensembles: Application to electrochemical determination of metronidazole. Electrochim. Acta 2013, 106, 288-292. [CrossRef]

111. Mardegan, A.; Scopece, P.; Ugo, P.; Moretto, L.M. Ensembles of gold nanowires for the anodic stripping voltammetric determination of inorganic arsenic. J. Nanosci. Nanotechnol. 2014, 15, 1-6. [CrossRef]

112. Wang, Y.; Zhu, Y.; Chenb, J.; Zeng, Y. Amperometric biosensor based on 3D ordered freestanding porous Pt nanowire array electrode. Nanoscale 2012, 4, 6025-6031. [CrossRef] [PubMed]

113. Zhang, Y.; Zhou, Q.; Zhao, W.; Chu, W.; Zheng, J. Array of recessed gold nanoelectrodes formed with polymethylmethacrylate for individual detection of ascorbic acid, dopamine and uric acid. Electrochim. Acta 2016, 212, 25-31. [CrossRef]

114. Dincer, C.; Ktaich, R.; Laubender, E.; Hees, J.J.; Kieninger, J.; Nebel, C.E.; Heinze, J.; Urban, G.A. Nanocrystalline boron-doped diamond nanoelectrode arrays for ultrasensitive dopamine detection. Electrochim. Acta 2015, 185, 101-106. [CrossRef]

115. De Oliveira, R.A.G.; Zanoni, M.V.B. Highly ordered $\mathrm{TiO}_{2}$ nanotubes for electrochemical sensing of hair dye basic brown 17. Electroanalysis 2013, 25, 2507-2514. [CrossRef]

116. Lee, J.; Hong, M.H.; Han, S.; Na, J.; Kim, I.; Kwon, Y.J.; Lim, Y.b.; Choi, H.J. Sensitive and selective detection of HIV-1 RRE RNA using vertical silicon nanowire electrode array. Nanoscale Res. Lett. 2016, 11, 341-347. [CrossRef] [PubMed]

117. Moon, J.M.; Kim, Y.H.; Cho, Y. A nanowire-based label-free immunosensor: Direct incorporation of a PSA antibody in electropolymerized polypyrrole. Biosens. Bioelectron. 2014, 57, 157-161. [CrossRef] [PubMed] 
118. Hu, H.; Cao, L.; Li, Q.; Ma, K.; Yanb, P.; Kirk, D.W. Fabrication and modeling of an ultrasensitive label free impedimetric immunosensor for Aflatoxin B1 based on poly(ophenylenediamine) modified gold 3D nano electrode ensembles. RSC Adv. 2015, 5, 55209-55217. [CrossRef]

119. Viswanathan, S.; Rani, C.; Ribeiro, S.; Matos, C.D. Molecular imprinted nanoelectrodes for ultra sensitive detection of ovarian cancer marker. Biosens. Bioelectron. 2012, 33, 179-183. [CrossRef] [PubMed]

120. Silvestrini, M.; Fruk, L.; Moretto, L.M.; Ugo, P. Detection of DNA hybridization by methylene blue electrochemistry at activated nanoelectrode ensembles. J. Nanosci. Nanotechnol. 2015, 15, 3437-3442. [CrossRef] [PubMed]

121. Habtamu, H.B.; Sentic, M.; Silvestrini, M.; Leo, L.D.; Not, T.; Arbault, S.; Manojlovic, D.; Sojic, N.; Ugo, P. A sensitive electrochemiluminescence immunosensor for celiac disease diagnosis based on nanoelectrode ensembles. Anal. Chem. 2015, 87, 12080-12087. [CrossRef] [PubMed]

122. Sultana, R.; Reza, N.; Kay, N.J.; Schmueser, I.; Walton, A.J.; Terry, J.G.; Mount, A.R.; Freeman, N.J. Practical implications of using nanoelectrodes for bioanalytical measurements. Electrochim. Acta 2014, 126, 98-103. [CrossRef]

123. Yu, J.; Zhang, Y.; Liu, S. Enzymatic reactivity of glucose oxidase confined in nanochannels. Biosens. Bioelectron. 2014, 55, 307-312. [CrossRef] [PubMed]

124. Yu, J.; Luo, P.; Xin, C.; Cao, X.; Zhang, Y.; Liu, S. Quantitative evaluation of biological reaction kinetics in confined nanospaces. Anal. Chem. 2014, 86, 8129-8135. [CrossRef] [PubMed]

125. Selvam, A.P.; Prasad, S.; Barrett, T.W.; Kazmierczak, S.C. Electrical nanowell diagnostics sensors for rapid and ultrasensitive detection of prostate-specific antigen. Nanomedicine (Lond.) 2015, 10, 2527-2536. [CrossRef] [PubMed]

126. Lu, J.; Li, H.; Cui, D.; Zhang, Y.; Liu, S. Enhanced enzymatic reactivity for electrochemically driven drug metabolism by confining cytochrome $\mathrm{P} 450$ enzyme in $\mathrm{TiO}_{2}$ nanotube arrays. Anal. Chem. 2014, 86, 8003-8009. [CrossRef] [PubMed]

127. Li, C.Y.; Tian, Y.W.; Shao, W.; Yuan, C.G.; Wang, K.; Xia, X.H. Solution pH regulating mass transport in highly ordered nanopore array electrode. Electrochem. Commun. 2014, 42, 1-5. [CrossRef]

128. Dickey, M.D.; Lipomi, D.J.; Bracher, P.J.; Whitesides, G.M. Electrically addressable parallel nanowires with $30 \mathrm{~nm}$ spacing from micromolding and nanoskiving. Nano Lett. 2008, 8, 4568-4573. [CrossRef] [PubMed]

129. Arumugam, P.U.; Chen, H.; Siddiqui, S.; Weinrich, J.A.P.; Jejelowo, A.; Li, J.; Meyyappan, M. Wafer-scale fabrication of patterned carbon nanofiber nanoelectrode arrays: A route for development of multiplexed, ultrasensitive disposable biosensors. Biosens. Bioelectron. 2009, 24, 2818-2824. [CrossRef] [PubMed]

130. Xiang, Y.; Keilbach, A.; Codinachs, L.M.; Nielsch, K.; Abstreiter, G.; Morral, A.F.I.; Bein, T. Multiple nanowire species synthesized on a single chip by selectively addressable horizontal nanochannels. Nano Lett. 2010, 10, 1341-1346. [CrossRef] [PubMed]

131. Dawson, K.; Wahl, A.; Barry, S.; Barrett, C.; Sassiat, N.; Quinn, A.J.; O’Riordan, A. Fully integrated on-chip nano-electrochemical devices for electroanalytical applications. Electrochim. Acta 2014, 115, 239-246. [CrossRef]

(C) 2016 by the authors; licensee MDPI, Basel, Switzerland. This article is an open access article distributed under the terms and conditions of the Creative Commons Attribution (CC-BY) license (http://creativecommons.org/licenses/by/4.0/). 